PNL-10112

\title{
Gas Distribution Effects on Waste Properties: \\ Viscosities of Bubbly Slurries
}

P. A. Gauglitz

R. R. Shah

R. L. Davis

September 1994

Prepared for

the U.S. Department of Energy

under Contract DE-AC06-76RLO 1830

Pacific Northwest Laboratory

Richland, Washington 



\section{DISCLAIMER}

This report was prepared as an account of work sponsored by an agency of the United States Government. Neither the United States Government nor any agency thereof, nor any of their employees, make any warranty, express or implied, or assumes any legal liability or responsibility for the accuracy, completeness, or usefulness of any information, apparatus, product, or process disclosed, or represents that its use would not infringe privately owned rights. Reference herein to any specific commercial product, process, or service by trade name, trademark, manufacturer, or otherwise does not necessarily constitute or imply its endorsement, recommendation, or favoring by the United States Government or any agency thereof. The views and opinions of authors expressed herein do not necessarily state or reflect those of the United States Government or any agency thereof. 


\section{DISCLAIMER}

Portions of this document may be illegible in electronic image products. Images are produced from the best available original document. 


\section{Executive Summary}

- Pacific Northwest Laboratory (PNL) ${ }^{(a)}$ is studying the physical mechanisms and waste properties that contribute to the periodic release of gases from the double-shell waste storage tanks at Hanford. This study is being conducted for Westinghouse Hanford Company as part of the PNL Flammable Gas project.

The retention and episodic release of flammable gases are critical safety concerns for doubleshell tanks that contain waste slurries. The rheological behavior of the waste, particularly of the settled sludge, is critical to characterizing the tendency of the waste to retain gas bubbles. The presence of gas bubbles is expected to affect the rheology of the sludge, but essentially no literature data are available to assess the effect of bubbles. Accordingly, the objectives of this study are to develop models for the effect of gas bubbles on the viscosity of a particulate slurry, develop an experimental method (capillary rheometer), collect data on the viscosity of a bubbly slurry, and develop a theoretical basis for interpreting the experimental data from the capillary rheometer.

Two models are developed to account for the effect of gas bubbles on the viscosities of particulate slurries. In the first method, bubbles are treated as solid particles that fit in the spaces between the actual particles. In the second approach, the bubbles contribute a yield stress to the slurry. The viscosity of the bubbly slurry is a combination of shear thinning term due to the particles and the additional yield stress due to the bubbles. In both cases, the models predict an increase in viscosity due to the bubbles.

To quantify experimentally the effect of bubbles on sludge properties, a capillary rheometer suitable for studying bubbly slurries was developed. The theory for analyzing data from the capillary rheometer is presented here in detail. The analysis shows that the method is valid for bubbly slurries, including the expected complexity of the bubbly slurry that possesses a yield stress and that slips at the capillary wall.

Experimental results have been obtained for bubbly slurries, slurries without bubbles, and simple Newtonian fluids, including water and glycerol/water mixtures. The experiments with Newtonian fluids were conducted to validate the new apparatus. The measurements on slurries were conducted to collect baseline data. Studies with bubbly slurries used the same slurry as without bubbles to highlight the effect of the bubbles.

For the slurry measurements, 50 vol\% of glass beads ( 90 microns) were mixed with 50 vol\% of a liquid composed of $80 \mathrm{wt} \%$ glycerol in $20 \mathrm{wt} \%$ water. The particles increased the viscosity about ten-fold over the same glycerol/water mixture without particles. For experiments with bubbles, $50 \mathrm{vol} \%$ of glass beads (90 microns) were again mixed with $50 \mathrm{vol} \%$ of a liquid, but the liquid was a mixture of gas bubbles and $80 \mathrm{wt} \%$ glycerol in $20 \mathrm{wt} \%$ water. Bubble loadings of 12.5 and 25 vol\%

(a) Pacific Northwest Laboratory is operated for the U.S. Department of Energy by Battelle Memorial Institute under Contract DE-AC06-76RLO 1830. 
were investigated. The bubbles were about the same size as the particles, based on observations with a microscope. The bubbles increased the viscosity of the slurry about five-fold for a bubble loading of $25 \mathrm{vol} \%$.

Future experimental studies will seek to control better the bubble size and volume fraction and will also seek to cover a broader range of bubble sizes and volume fractions. Future theoretical investigations will focus on developing improved models for the role of bubble size and volume fraction on the viscosities of bubbly slurries. 


\section{Acknowledgments}

The authors would like to thank the following contributors for support in this project: Mike Miller for selecting the equipment for capillary rheometer, overseeing its construction, and programming much of the data acquisition system; Loni Peurrung for expert assistance in programming the data acquisition system; Professor William R. Rossen of the University of Texas at Austin for help in selecting the experimental approach; Larry Pederson for his input to this study; and Randy Odd and Rick Walker of crafts services for construction of the capillary rheometer. And Rayford L. Davis acknowledges support from the Life-Gets-Better Scholarship program at the Pacific Northwest Laboratory. 
, 


\section{Contents}

Executive Summary $\ldots \ldots \ldots \ldots \ldots \ldots \ldots \ldots \ldots \ldots \ldots \ldots \ldots \ldots$ iii

Acknowledgments $\ldots \ldots \ldots \ldots \ldots \ldots \ldots \ldots \ldots \ldots \ldots \ldots \ldots \ldots \ldots \ldots$

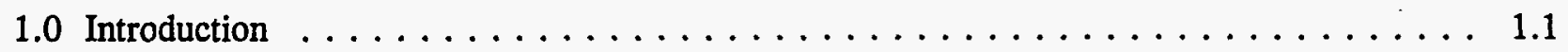

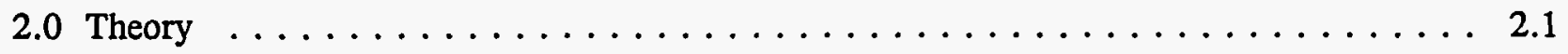

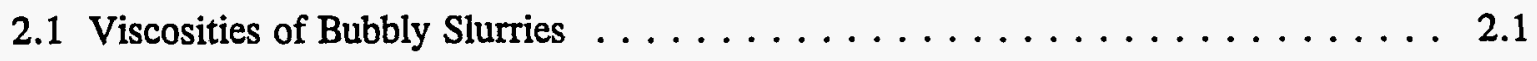

2.1.1 Concentrated Bubbles-as-Particles Suspension Model $\ldots \ldots \ldots \ldots \ldots$. . . 2.1

2.1.2 Yield-Stress Model . . . . . . . . . . . . . . . . 2.4

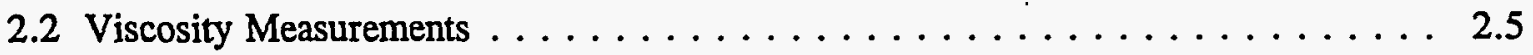

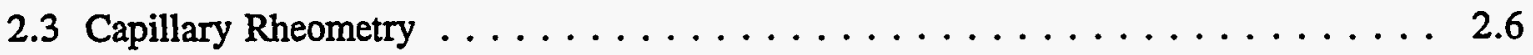

3.0 Experimental Method and Materials $\ldots \ldots \ldots \ldots \ldots \ldots \ldots \ldots \ldots \ldots \ldots \ldots \ldots$

3.1 Viscosity Measurements $\ldots \ldots \ldots \ldots \ldots \ldots \ldots \ldots \ldots \ldots \ldots \ldots$

3.2 Test of the Capillary Rheometer $\ldots \ldots \ldots \ldots \ldots \ldots \ldots \ldots \ldots \ldots \ldots \ldots$

4.0 Results and Discussion $\ldots \ldots \ldots \ldots \ldots \ldots \ldots \ldots \ldots \ldots \ldots \ldots \ldots$

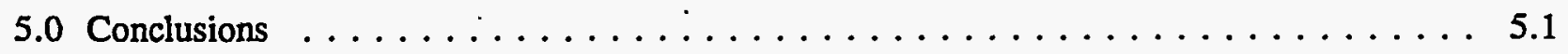

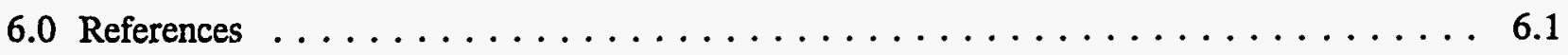

Appendix A: Capillary Rheometry Theory $\ldots \ldots \ldots \ldots \ldots \ldots \ldots \ldots \ldots \ldots$

Appendix B: Examples of Capillary Rheometry Data Analysis $\ldots \ldots \ldots \ldots \ldots \ldots$. . . . . B.1

Appendix C: Pressure and Flow Data $\ldots \ldots \ldots \ldots \ldots \ldots \ldots \ldots \ldots \ldots \ldots \ldots$ 


\section{Figures}

2.1 Effect of Particle and Gas Fraction on the Viscosity of a Bubbly Slurry $\ldots \ldots \ldots \ldots$

2.2 Effect of Combined Particle and Gas Fraction on the Viscosity of a Bubbly Slurry $\ldots \ldots$. . 2.4

2.3 Flow of a Non-Newtonian Fluid with Wall Slip in a Cylindrical Capillary $\ldots \ldots$. . . . 2.7

3.1 Capillary Rheometer Apparatus for Measuring the Viscosities of Bubbly Slurries . . . . . 3.2

3.2 Viscosity of $80 \mathrm{wt} \%$ Glycerol in $20 \mathrm{wt} \%$ Water Mixture as a Function of Shear Rate . . . 3.3

3.3 Viscosity of Water as a Function of Shear Rate $\ldots \ldots \ldots \ldots \ldots \ldots$

4.1 Viscosities of Slurries with and Without Bubbles $\ldots \ldots \ldots \ldots \ldots \ldots$ 


\subsection{Introduction}

Retention and episodic releases of flammable gases are critical safety concerns regarding double-shell tanks (DSTs) containing waste slurries. Evidence suggests that slurry waste stored in some of the DSTs separates into an upper convective layer and a lower nonconvective layer of sludge, with part of the generated gas collecting as bubbles in the lower nonconvective sludge (Allemann et al. 1990a, 1990b, 1991, 1993). The formation of bubbles, their retention, and their release are central to understanding and predicting the volume and rate of gas released during a gas release event (Trent and Michener 1993).

The rheological behavior of the waste, particularly of the settled sludge, is critical to characterizing the tendency of the waste to retain gas bubbles. Accordingly, a number of studies have focused on measuring the rheology of simulated and actual DST waste (Bryan et al. 1992; Tennant et al. 1993; Allemann 1990a; Herting 1991; Reynolds 1992; Hall 1993). ${ }^{\text {(a) }}$ The presence of gas bubbles in the particulate slurry, which we will refer to as a bubbly slurry, is expected to affect the rheology of the sludge. However, essentially no literature data are available to assess the effect of bubbles, although Tennant et al. (1993, p. 53) noted that air bubbles increased the viscosity (less than $50 \%$ ) of slurries that emulated tank waste. In these experiments, the volume fraction of air was not determined but was likely quite small. In other applications with high concentrations of gas bubbles, which are commonly called foams, bubbles have been shown to greatly increase the viscosity of a fluid (Kraynik 1988). In contrast, viscosity of a bubbly fluid can be reduced if the gas bubbles distort without resistance, which can occur with large bubbles or negligible surface tension. Thus, while there is evidence that gas bubbles will affect the rheology of a slurry, the magnitude of the effect is not known.

Gas bubbles are also expected to affect the shear strength of settled solids, and some literature data on particle agglomeration quantify the effect of the gas fraction. These data have been reviewed recently, and a correlation that fits literature data on the tensile strength of moist agglomerates was developed. ${ }^{(b)}$

The objectives of this study were to develop models for the effect of gas bubbles on the viscosity of a particulate slurry, to develop an experimental method and collect data on the viscosity of a bubbly slurry, and to develop a theoretical basis for interpreting the experimental data. In Section 2.0 we present two models for testing the viscosities of bubbly slurries, discuss methods for measuring their viscosities, and describe the theoretical basis for interpreting data from the capillary rheometer, which was chosen as a suitable device for making these measurements. In developing the equations for interpreting the data, special attention was given to any assumptions or limitations that

(a) Two unpublished reports also contain results of studies on the rheology of simulated and actual DST waste: Rheological Properties of Waste from Tank 101-SY, by J. M. Tingey (PNL) (1992); and $A$ Theoretical and Experimental Study of Waste Tank Sludge Rheology Within a Hot Spot or During Draining, letter report to WHC by D. O. Campbell (1993).

(b) Gauglitz, P. A., and L. A. Mahoney. 1994. An Improved Bubble Release Theory. Letter Report, Pacific Northwest Laboratory, Richland, Washington. 
relate to the effect of the gas bubbles. One expected effect is slip at the capillary wall, and the equations to account for this are presented. A capillary rheometer capable of investigating bubbly slurries has been constructed. In Section 3 we describe this apparatus and present data that validate the apparatus and data analysis method. Finally, Section 4 contains viscosity data for bubbly slurries and slurries without bubbles. 


\subsection{Theory}

\subsection{Viscosities of Bubbly Slurries}

The viscosity of a suspension is greater than the viscosity of the suspending fluid due to the interactions between the particles as they move relative to one another. Depending on the physical situation, the presence of gas bubbles can either increase or decrease the viscosity of a slurry. Because the bubbles occupy space and resist deformation due to surface tension, the bubbles will force the particles closer together. This increases the interactions between the particles and thus increases the viscosity of the bubbly suspension. If the bubble must deform for the suspension to shear, then the resistance to deformation needs to include bubble deformation. However, the gas within the bubble is much less viscous than the suspension and can therefore also act as an internal lubricant. For this to be the case, the resistance to bubble deformation must be negligible; this should occur for negligible surface tension or relatively large bubbles (larger than a few $\mathrm{mm}$ in diameter).

In the following sections, we present two mathematical models for the effect of bubbles on the viscosities of concentrated suspensions. We will develop expressions from two perspectives. First, we will assume that the gas bubbles behave as solid particles that fit between the solid particles. A second approach will follow studies of bulk foam rheology. For bulk foams, the dominant behavior is a yield stress that depends on gas fraction, bubble size, and surface tension. So in this approach we will add a yield stress to the particle suspension viscosity where the yield stress depends on the bubble volume fraction, bubble size, and surface tension.

Two results from suspension rheology are important. First, for the viscosity of a concentrated suspension, the effect of particle volume fraction $\phi_{\mathrm{p}}$ is best included in relation to the maximum packing fraction $\phi_{\mathrm{m}}$ of the dispersed phase (Barnes et al. 1989). Thus the solids fraction will appear in the equations as the ratio $\phi_{\mathrm{p}} / \phi_{\mathrm{m}}$ for concentrated suspensions. Second, for dilute suspensions of particles, or small bubbles that behave as solid particles, the Einstein result relates the suspension viscosity, $\eta$, to the volume fraction of the dispersed phases. For both particles and bubbles, the Einstein result is (Barnes et al. 1989)

$$
\frac{\eta}{\eta_{f}}=1+2.5 \phi_{p}+2.5 \phi_{g}
$$

where $\eta_{f}$ is the viscosity of the suspending fluid, and $\phi_{g}$ is the volume fraction of gas bubbles. Any reasonable theory for concentrated suspensions should reduce to Equation 1 in the limit of small $\phi_{\mathrm{g}}$ and $\phi_{\mathrm{p}}$.

\subsubsection{Concentrated Bubbles-as-Particles Suspension Model}

To derive an expression for the effect of gas bubbles and solid particles on suspension viscosity, we' extend the development of Ball and Richmond (Barnes et al. 1989). This 
phenomenological approach assumes that the incremental viscosity due to adding particles is additive. The approach begins with the differential form of Equation 1:

$$
d \eta=\frac{5 \eta}{2} d \phi_{p}
$$

For concentrated suspensions, the change in volume fraction $d \phi_{\mathrm{p}}$ is modified to account for "crowding" due to particle interactions (Barnes et al. 1989):

$$
d \eta=\frac{5 \eta}{2} \frac{d \phi_{p}}{1-\phi_{p} / \phi_{m}}
$$

We now modify this result to include bubbles but retain the effect of particles as given by Equation 3. Because gas bubbles can distort, all of the space between the solid particles, which is $1-\phi_{\mathrm{p}}$, can be filled with gas. Accordingly, Equation 3 modified to include gas bubbles becomes

$$
d \eta=\frac{5 \eta}{2}\left[\frac{d \phi_{p}}{1-\phi_{p} / \phi_{m}}+\frac{d \phi_{g}}{1-\left[\phi_{g} /\left(1-\phi_{p}\right)\right]}\right]
$$

where the gas fraction is scaled by the fraction of space between the particles to account for crowding. Integration yields the final result for the effect of gas bubbles on the viscosity of a suspension of particles:

$$
\frac{\eta}{\eta_{f}}=\left(1-\frac{\phi_{p}}{\phi_{m}}\right)^{\frac{-5 \phi_{m}}{2}}\left(1-\frac{\phi_{g}}{\left(1-\phi_{p}\right)}\right)^{-\frac{5}{2}}
$$

This result reduces to the Einstein relation, Equation 1, when expanded in a Taylor series for small $\phi_{g}$ and $\phi_{\mathrm{p}}$.

The physical situation implied by this model is one in which the gas bubbles behave as small solid particles that fit between the larger real particles. Thus this result neglects the effects of bubble size and surface tension. A more correct physical model would 1) have bubbles distorting to fit between the particles and then 2) account for bubble deformation as the bubbly slurry shears. In summary, the advantage of Equation 5 is its simplicity, but some clearly important physical effects have been neglected. Experimental data are required to determine the validity of Equation 5 .

Figure 2.1 shows the reduced suspension viscosity, determined by Equation 5 , as a function of particle fraction for a range of particle and gas fractions. The viscosity increases rapidly as the particle fraction approaches the maximum packing fraction. As shown in Figure 2.1, gas bubbles 
increase the suspension viscosity. Figure 2.2 shows the same result plotted as a function of the total volume fraction of particles and bubbles. This figure shows the Einstein limit for small particle and bubble fractions.

The effect of shear rate on viscosity can be combined with Equation 5 using any of a number of correlations. Mahoney et al. (1994) have critiqued these correlations recently. As an example, combining a power law expression with Equation 5 gives the following result for viscosity:

$$
\eta=K|\dot{\gamma}|^{n-1}\left(1-\frac{\phi_{p}}{\phi_{m}}\right)^{\frac{5 \phi_{m}}{2}}\left(1-\frac{\phi_{g}}{\left(1-\phi_{p}\right)}\right)^{-\frac{5}{2}}
$$

where $\dot{\gamma}$ is the shear rate and $K$ and $\eta$ are material-dependent constants.

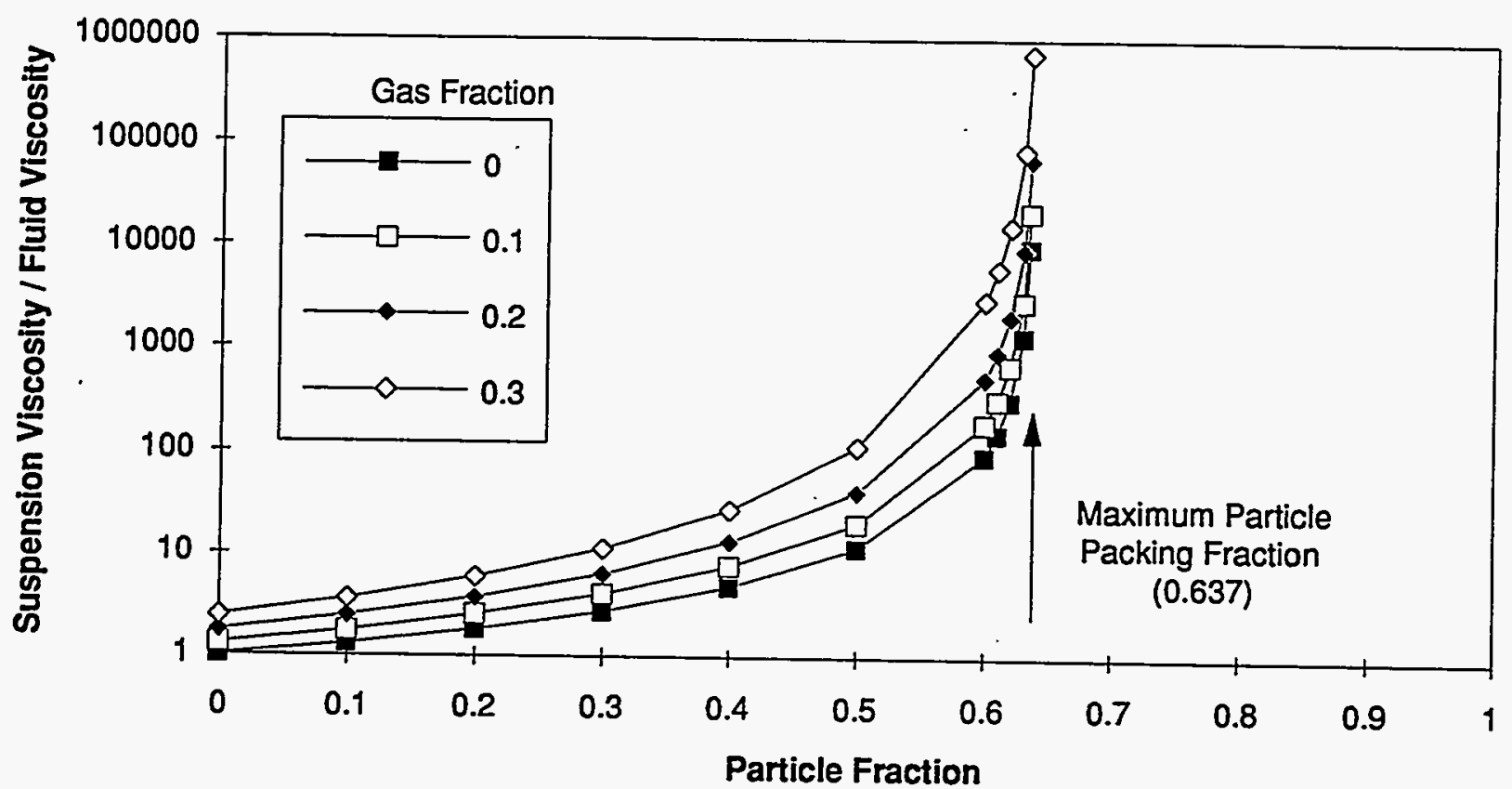

Figure 2.1. Effect of Particle and Gas Fraction on the Viscosity of a Bubbly Slurry 


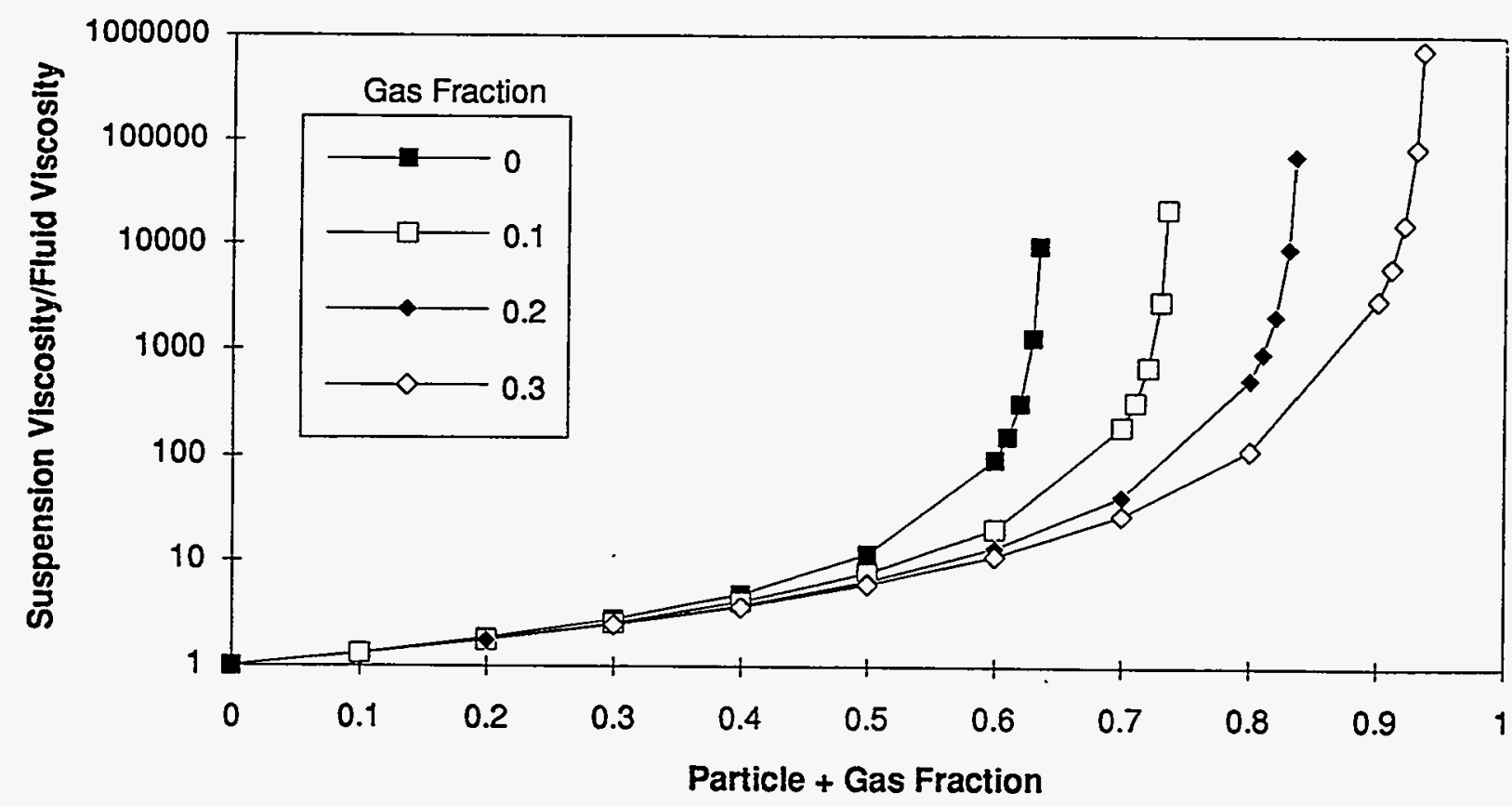

Figure 2.2. Effect of Combined Particle and Gas Fraction on the Viscosity of a Bubbly Slurry

\subsubsection{Yield-Stress Model}

A second method of accounting for the effect of bubbles on viscosity is to assume the bubbles contribute a yield stress when the packing fraction is high. This approach is commonly used for bulk foams (Kraynik 1988). In this case, the bubbly slurry viscosity, $\eta$, can be represented by

$$
\eta\left(\dot{\gamma}, \phi_{p}, \phi_{g}\right)=g\left(\dot{\gamma}, \phi_{p}\right)+\tau_{y}\left(\phi_{g}\right) / \dot{\gamma}
$$

where $g\left(\dot{\gamma}, \phi_{p}\right)$ is a shear rate-dependent constitutive relation. For bulk foams, Princen (1985) has suggested, based on experimental evidence, that the yield stress can be represented by $\left.\tau_{\mathrm{y}}=\sigma \phi_{\mathrm{g}}^{1 / 3} F\left(\phi_{\mathrm{g}}\right) /<R_{b u b}\right\rangle$, where $\sigma$ is the surface tension, $\left\langle R_{b u b}\right\rangle$ is the mean bubble size, and $F\left(\phi_{\mathrm{g}}\right)$ is an increasing function of $\phi_{\mathrm{g}}$ determined from experimental data. Analogous to this and similar results for concentrated foams and emulsions, the yield stress for a bubbly slurry can be represented by Equation 8 (Kahn et al. 1988; Kraynik 1988; Yoshimura et al. 1987; Pal and Rhodes 1989):

$$
\tau_{y}=\frac{\sigma}{\left\langle R_{b u b}\right\rangle} f\left(\frac{\phi_{g}}{1-\phi_{p}}\right)
$$


where again the gas fraction has been scaled by the space available between the particles $\left(1-\phi_{\mathrm{p}}\right)$. With this expression for the yield stress, the viscosity of a bubbly suspension becomes

$$
\eta=K|\dot{\gamma}|^{n-1}\left(1-\frac{\phi_{p}}{\phi_{m}}\right)^{\frac{-5 \phi_{m}}{2}}+\frac{\sigma}{<R_{b u b}>} f\left(\frac{\phi_{g}}{1-\phi_{p}}\right)|\dot{\gamma}|^{-1}
$$

where we have assumed a power law expression for the particulate term. This equation gives more varied results than Equation 6, and the effect of bubble deformation is included by the yield stress. Also, the relative contribution of the particulate and bubble terms now vary; in Equation 6, the relative contribution was fixed. The shear rate dependence is also different. For the "bubbles-as-particles" model, the shear rate dependence for bubbles and particles is identical. For the yield stress model given by Equation 9, the bubbles contribute a Bingham term, and the particles contribute a different shear thinning effect.

The relative contribution of the viscous and yield stress terms to the slurry viscosity is given by the ratio of the two terms in Equation 9:

$$
C a=\frac{\left(K|\tilde{\gamma}|^{-1}\right)\left(<R_{b u b}>|\tilde{\gamma}|\right)}{\sigma} F\left(\phi_{p}, \phi_{g}, \phi_{m}\right)
$$

where $\bar{\gamma}$ is a characteristic shear rate. This ratio of viscous to surface tension is a modified capillary number (Ca). When the capillary number is large, viscous forces due to the particles dominate, and bubbles have a negligible effect. When the capillary number is small, the yield stress contribution due to bubbles is important.

\subsection{Viscosity Measurements}

Experimental shear viscosity data are required to test the models given above for the effect of gas bubbles on the viscosity of a slurry. A wide variety of methods exist for measuring the shear viscosities of complex fluids. Instruments for measuring shear viscosity can be generally classified as rotational, shop-floor, and capillary and slit flow devices (Barnes et al. 1989). Rotational devices include concentric cylinders, parallel plates, and cone-and-plate geometries. While these devices are very effective for homogeneous fluids, they are often difficult to use with slurries when the particles settle or when the particle size is not much smaller that the gap size. Cone-and-plate devices are particularly difficult to use with slurries because the gap size is typically quite small. For bubbly slurries, the tendency of the bubbles to rise and leave the slurry make rotational devices even more difficult to use effectively. Shop-floor devices encompass a tremendous variety of flow geometries. In general, the flow fields in these devices are very complex, and complicated theoretical derivations are necessary to obtain viscosity information. Accordingly, these devices are generally used to give empirical data. 
Capillary and slit flow devices determine the fluid viscosity from data on the flow and pressure drop of a fluid moving through a cylindrical capillary or a slit. Capillary devices are generally considered very effective for studying slurries. For bubbly slurries, the capillary devices have an advantage, because bubbles flowing within the capillary cannot leave the device (although they can still segregate from the slurry). Apparatuses based on capillary flow have been used to investigate both foams and foams with suspended solids (Reidenbach et al. 1986; Harris and Reidenbach 1987; Patton et al. 1983; Kraynik 1988; Thondavadi 1983). Because of the potential advantages of measuring the viscosity of a bubbly slurry with a capillary-flow device, we chose this geometry for collecting viscosity data. In the following section, the theory for determining viscosity from capillary flow data is discussed.

\subsection{Capillary Rheometry}

Figure 2.3 shows the situation of a non-Newtonian fluid with a yield stress flowing through a cylindrical capillary where the fluid slips along the capillary wall. The capillary rheometry method allows the viscosity of any time-independent fluid, such as the one depicted in Figure 2.1 , to be obtained from flow rate pressure drop data. Thus thixotropic suspensions are excluded in general from this analysis. The traditional theoretical analysis begins with an integral equation for flow rate, changes variables from radial position to shear stress, and then differentiates the resulting integral equation with respect to the wall shear stress. The resulting equations give viscosity as a function of shear rate without assuming any model for the fluid. Appendix A gives a detailed derivation of these equations. The analysis gives the following expression (Equation A.14) for the shear rate $\dot{\gamma}_{w}$ at the capillary wall,

$$
\dot{\gamma}_{w}=\frac{4\left(Q-\pi R^{2} V_{w}\right)}{\pi R^{3}}\left(\frac{3}{4}+\frac{1}{4} \frac{d \ln \left(Q-\pi R^{2} V_{w}\right)}{d \ln \tau_{w}}\right)
$$

where $Q$ is the volumetric flow through the capillary, $V_{w}$ is the slip velocity, and $R$ is the tube radius. The shear stress at the capillary wall, $\tau_{w}$, which, by convention, is positive, is defined below (and in Equation A.3).

$$
\dot{\tau}_{w}=\frac{R}{2}\left(\frac{-\Delta P}{L}\right)
$$

where $\Delta P / L$ is the pressure drop per length of tubing: The viscosity at the capillary wall, where the shear rate is given by. Equation 11, is the ratio of the shear stress to the shear rate (Equation A.13). 


$$
\eta_{w}=\frac{\tau_{w}}{\dot{\gamma}_{w}}
$$

Although the shear rate and therefore the viscosity of the material vary over the cross section of a capillary, this method results in a viscosity measurement at a position (capillary wall) where the shear rate can be determined.

To calculate the viscosity as a function of shear rate, a log-log plot of pressure drop (plotted as $\tau_{\mathrm{w}}$ ) as a function of flow rate is developed. The slope is determined at each flow, which is the last term in Equation 11, and the shear rate is determined with Equation 11. The viscosity is then determined with Equation 13. In Appendix B a numerical algorithm for determining these slopes and

$\dot{\gamma}_{w}$ is-described, and examples that validate the numerical algorithm against exact analytic solutions are given. Section A.2 of Appendix A describes how to determine the slip velocity, $V_{w}$, from experimental data. We assumed $\mathrm{V}_{\mathrm{w}}=0$ for the data we analyzed in the following sections.

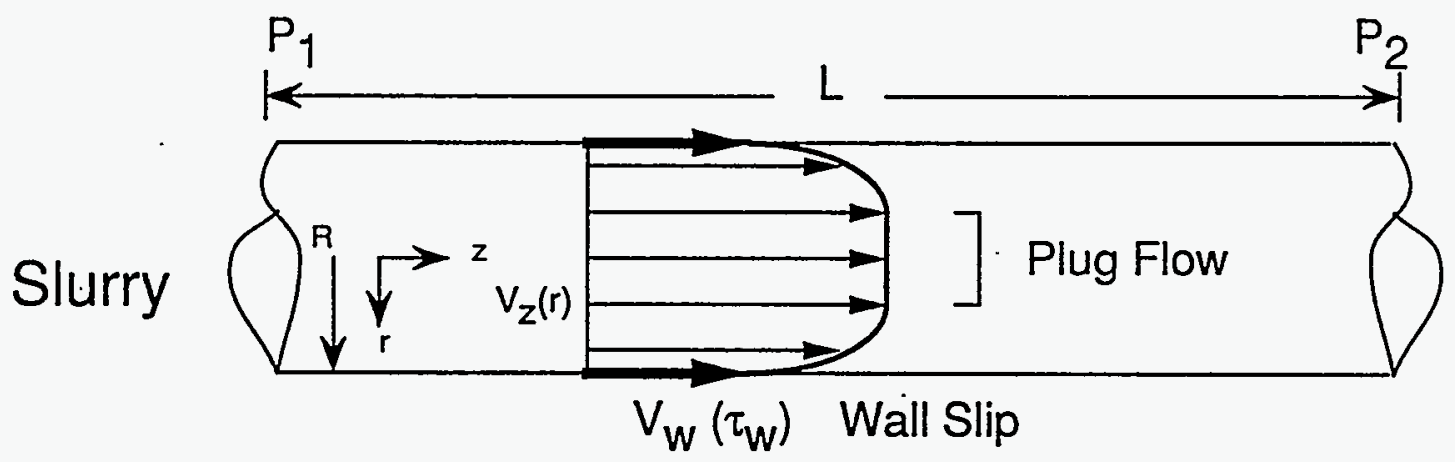

Figure 2.3. Flow of a Non-Newtonian Fluid with Wall Slip in a Cylindrical Capillary 


\subsection{Experimental Method and Materials}

\subsection{Viscosity Measurements}

A schematic of a capillary rheometer apparatus for measuring the viscosities of bubbly slurries is shown in Figure 3.1. In the test section, valves allow the fluid to flow through either of two tubes. If a fluid slips along the walls of the capillary, different diameter capillaries will give different viscosities, and the diameter dependence of the viscosity can be used to correct for this effect (see Appendix A). For the slurry experiments, the apparatus used a larger tube (nominal $1 / 2$ in.) with an internal diameter of $0.96 \mathrm{~cm}$ and a length of $702 \mathrm{~cm}$. The second, smaller tube (nominal $3 / 8$ in.) had an internal diameter of $0.66 \mathrm{~cm}$ and was $133 \mathrm{~cm}$ long. Both were made of clear polyvinyl chloride (PVC), ${ }^{(a)}$ allowing the bubbles and particles to be viewed within the tubes. The relative lengths of the tubes were chosen so the pressure drop across each was similar at similar flow rates, allowing improved comparisons of data collected in the different tubes. Pressures were measured with two absolute pressure transducers, ${ }^{(b)}$ each with a pressure range of $0-310 \mathrm{kPa}(0-45 \mathrm{psia})$ and a $0.01 \%$ accuracy $(0.0045$ psia) traceable to NIST standards. The difference between the two absolute pressure measurements gave the pressure difference across the tubes with an accuracy of $62 \mathrm{~Pa}(0.009$ psia). The transducers were connected to a Digiquartz Pressure Computer, which included a temperature compensation feature as part of the pressure transducer calibration. ${ }^{(c)}$

The slurry was displaced through the test section with a progressing cavity pump capable of delivering $1.3 \mathrm{cc} / \mathrm{s} .^{(d)}$ The pump was equipped with a speed controller that maintained the pump at selected rpm (revolutions per minute) settings ${ }^{(e)}$ and had a $1 / 4 \mathrm{hp} \mathrm{DC}$ electric motor, rated at 90 VDC and $1725 \mathrm{rpm}$, attached to a 50:1 gear reducer. ${ }^{(1)}$

Transparent cells for observing the bubbles were placed both upstream and downstream from the test section. These cells were constructed from lexan and had a viewing area $2.5 \mathrm{~cm}$ wide by 7.7 $\mathrm{cm}$ long. The depth of the viewing area was approximately $0.1 \mathrm{~cm}$, allowing the bubbles to be observed more easily. A fiber optic illuminator lighted the viewing area from behind. ${ }^{(8)}$ When

(a) Imperial Eastman, Itasca, Illinois.

(b) Paroscientific, Digiquartz model 245A-101.

(c)' Paroscientific model 702.

(d) Robbins \& Meyers Moyno, single-screw rotary pump, frame 2MISSQ, trim AAA; Moyno Products, Springfield, Ohio.

(e) Dart MD II, MD30E with pick-up CF-H60; Dart Controls Inc., Zionsville, Indiana.

(f) Model POA13K1; Sterling Electric Inc., Irvine, California.

(g) Cole Parmer model 41500-50. 


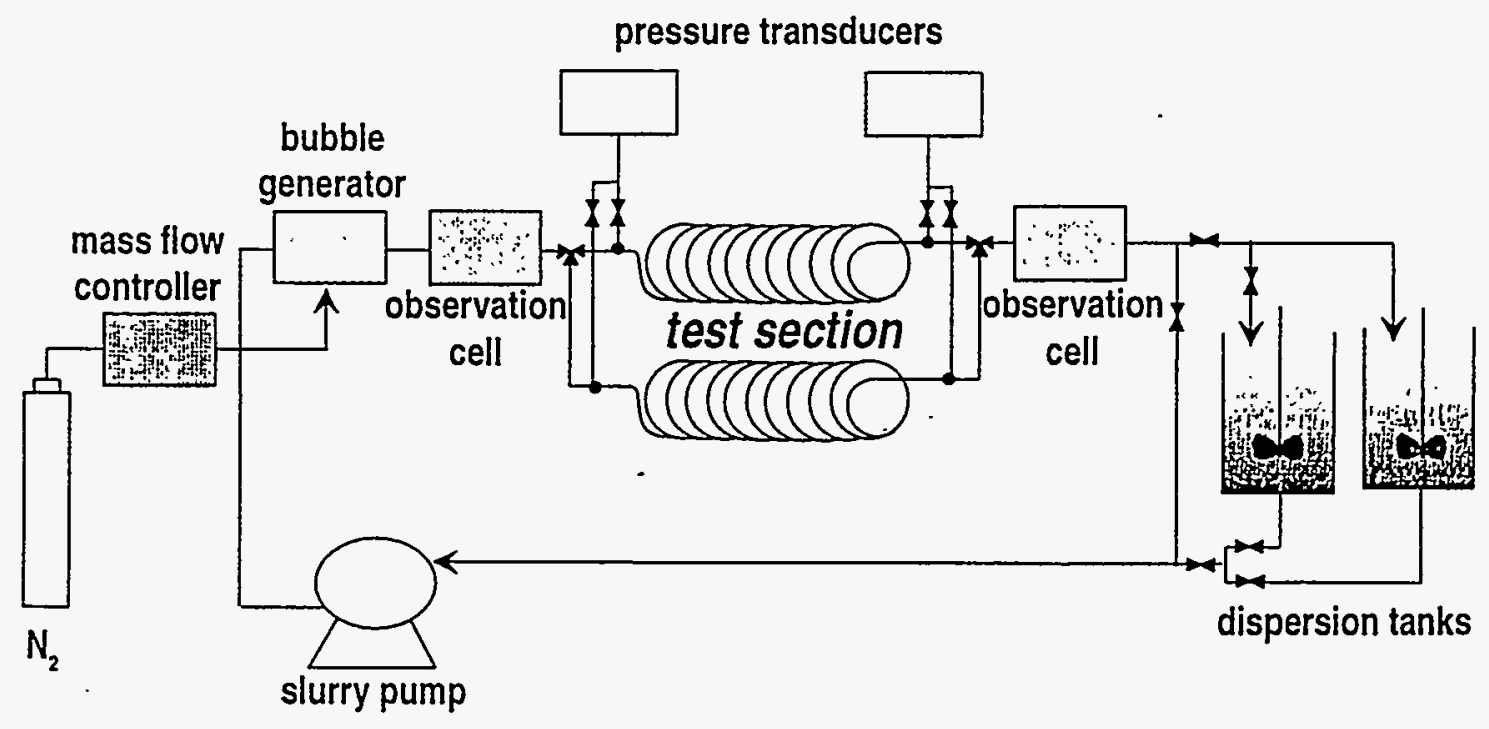

Figure 3.1 Capillary Rheometer Apparatus for Measuring the Viscosities of Bubbly Slurries

creating foam bubbles, nitrogen gas was metered from a cylinder with a mass flow controller. ${ }^{\text {(a) }}$ Two types of gas bubble generators were used. For the data we report in Section 4.0, gas and liquid were passed together through a piece of tubing packed with stainless steel wool. The intimate mixing in this tube created gas bubbles. This foam was then mixed with particles at the desired volume fraction of particles. To generate bubbles within the capillary rheometer apparatus, a stainless steel gas sparger was inserted in the flow line. Injecting gas through the frit created bubbles within the flow line; these bubbles were larger than the bubbles created with the packed tubing.

The capillary rheometer apparatus was automated for both data acquisition and control with LabVIEW for Windows software operating on a 486-PC. The computer control set the pump at any series of specified flows, then recorded pressure and flow data. The apparatus was also capable of being operated manually by setting the flows and reading the pressures from a digital readout.

Slurries were made from mixtures of glass beads, glycerol, and tap water. In the experiments with bubbles generated with the packed tubing described above, 1 wt\% Joy liquid detergent was added to the glycerol water mixtures and effectively eliminated bubble coalescence. The glass beads used in this study had a nominal diameter of 90 microns. ${ }^{(b)}$ The glycerol was an industrial grade material containing $5 \mathrm{wt} \%$ water. To achieve a desired viscosity of about $0.60 \mathrm{~Pa}^{*} \mathrm{~s}(60 \mathrm{cP})$ for a suspending fluid, which is similar to the viscosity of the convective layer in Tank $241-\mathrm{SY}-101$, $^{(\mathrm{c})}$

(a) Brooks model 5850E; Brooks Instruments, Hatfield, Pennsylvania.

(b) Jaygo Inc., Mahwh, New Jersey.

(c) Tingey, J. M. 1992. Rheological Properties of Waste from Tank 101-SY. Pacific Northwest Laboratory, Richland, Washington. 
$80 \mathrm{wt} \%$ glycerol was mixed with $20 \mathrm{wt} \%$ tap water. This mixture of glycerol and water was used in all the slurry experiments. All experiments were conducted at ambient room temperature, which ranged from 24 to $32^{\circ} \mathrm{C}$.

\subsection{Test of the Capillary Rheometer}

To test the capillary rheometer, we measured the viscosities of water and mixtures of water and glycerol, which are Newtonian fluids. Prior to the viscosity measurements, the flow was delivered by the slurry pump displacing water over a range of rpm settings. The water delivered by the pump at each setting was collected for a period of time and then weighed. The flow rate was calculated, assuming a water density of $1.0 \mathrm{~g} / \mathrm{cc}$, as the ratio of volume delivered over the time interval. The flow delivered by the pump was linear with the rpm setting, with a calibration constant of $27.16 \mathrm{rpm} /(\mathrm{cc} / \mathrm{min})$. This result was used in all subsequent experiments to determine the flow at any pump setting.

The viscosity of the $80 \mathrm{wt} \%$ glycerol in $20 \mathrm{wt} \%$ water mixture was measured for a range of shear rates using the two different tubes. Figure 3.2 shows the viscosity as a function of shear rate for the glycerol/water mixture in both of the capillaries. (Appendix $\mathrm{C}$ gives the pressure and flow data that were used to calculate the viscosity.) For a Newtonian fluid, the viscosity should not

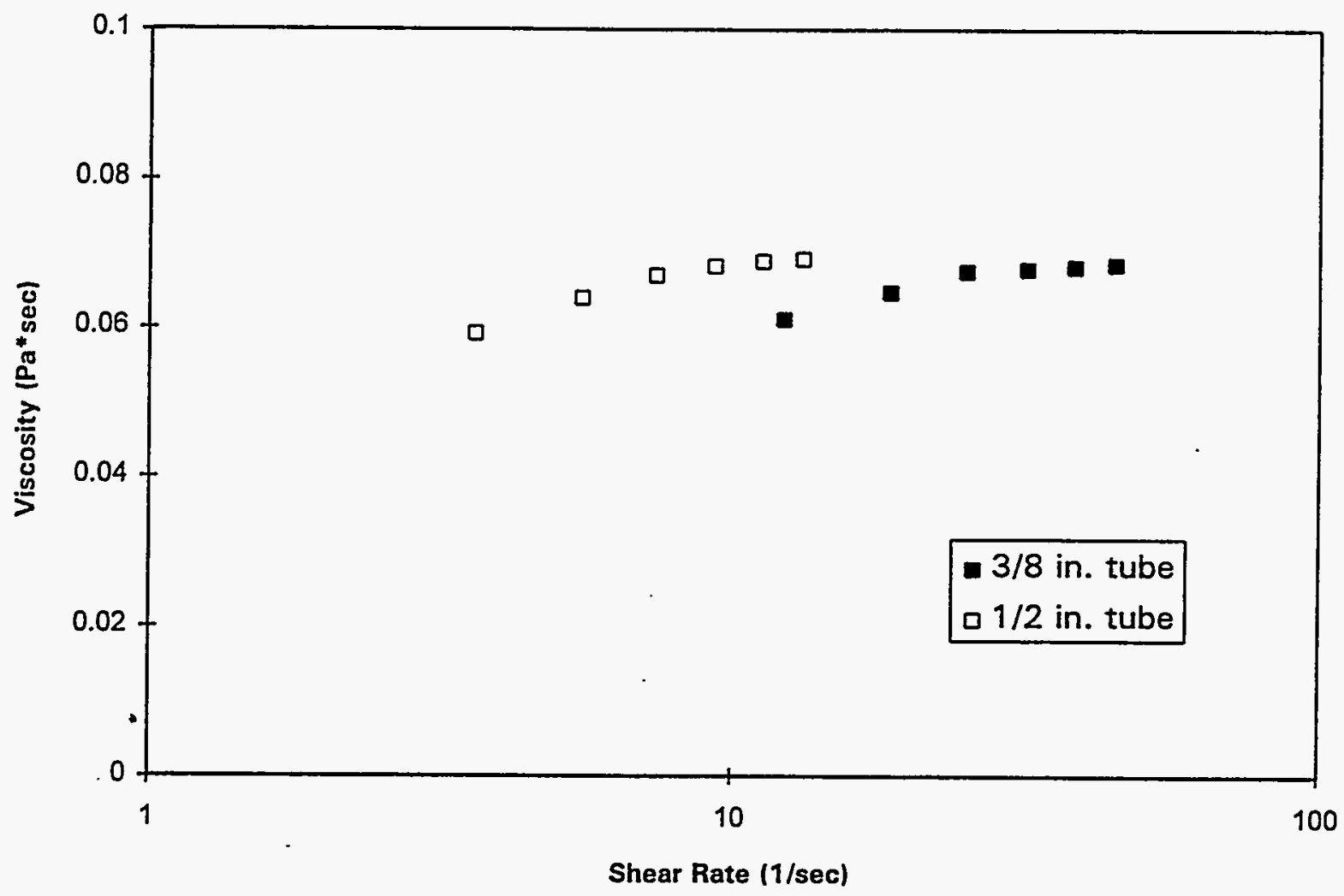

Figure 3.2. Viscosity of $80 \mathrm{wt} \%$ Glycerol in $20 \mathrm{wt} \%$ Water Mixture as a Function of Shear Rate 
depend on shear-rate, although the data show a weak shear rate dependence. At the highest shear rates, the largest Reynolds number (Denn 1980) was 3, so inertial effects of flowing in the coiled capillaries should be negligible. At these higher shear rates in each tube, the capillary rheometer gives a viscosity of $0.68 \mathrm{~Pa} * \mathrm{~s}(68 \mathrm{cP})$. A viscosity of $0.64 \mathrm{~Pa} * \mathrm{~s}(64 \mathrm{cP})$ was measured for an identical mixture in a conventional rotational viscometer, which agrees well with the capillary rheometer results. ${ }^{(a)}$ The small shear rate dependence, most noticeable at the lowest shear rate for each tube, is likely caused by errors in the pressure measurements. At the lowest shear rate in each tube, the measured pressure difference was $600 \pm 62 \mathrm{~Pa}(0.09 \pm 0.009 \mathrm{psig})$; this $10 \%$ error in the pressure measurement accounts for the variation in the measured viscosity.

Figure 3.3 shows viscosity data collected for water in a 306-cm-long capillary with an internal diameter of $0.20 \mathrm{~cm}$. At the lower flow rates, the viscosity of $1 \mathrm{cP}$ agrees with literature values for water $(1 \mathrm{cP})$. The increase in the apparent viscosity with increasing shear rate is likely because of additional dissipation caused by inertial effects. At the highest shear rate in Figure 3.2, the Reynolds

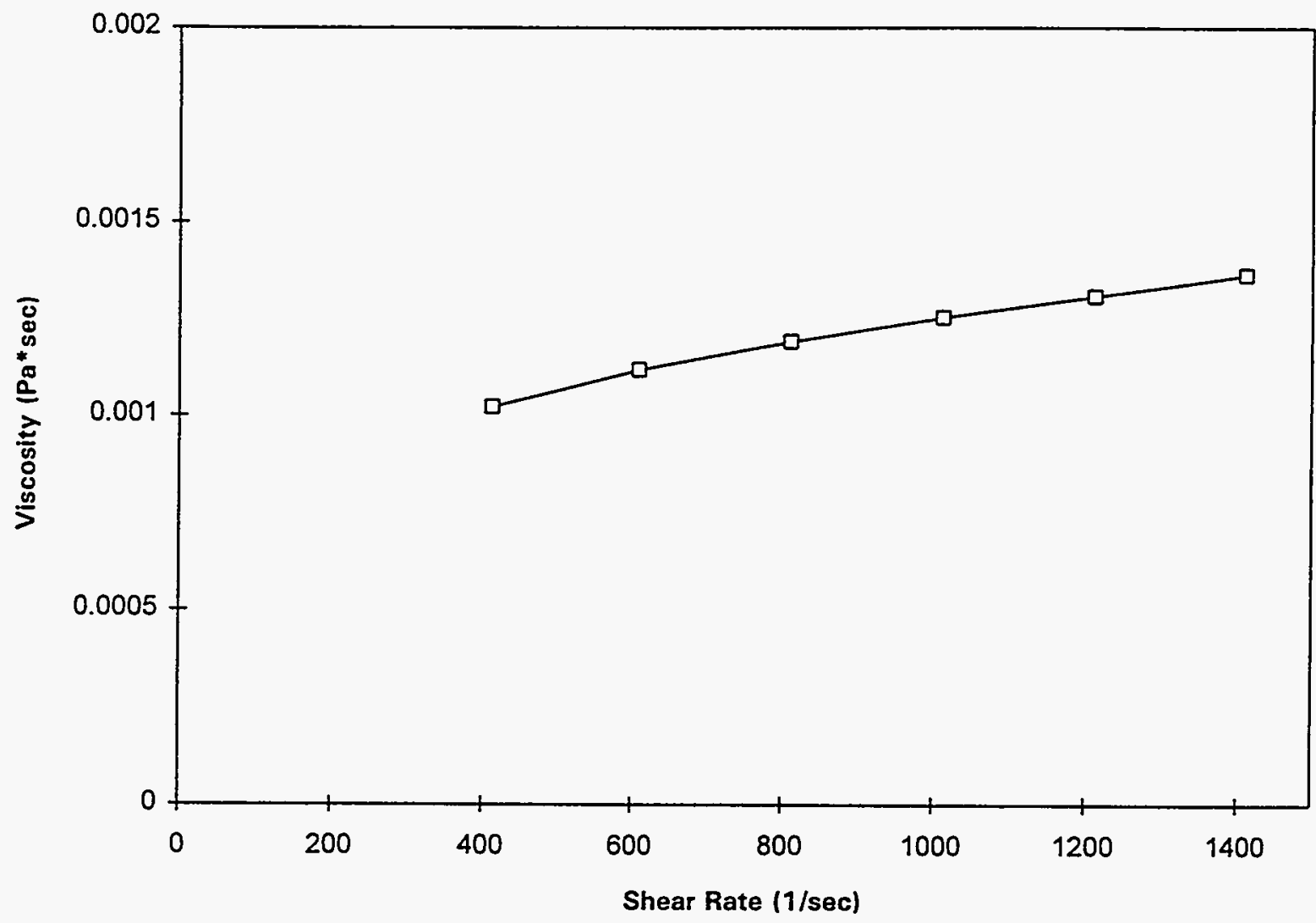

Figure 3.3 Viscosity of Water as a Function of Shear Rate

(a) An unpublished 1994 internal letter report gives viscosity data for this mixture of glycerol and water: DST Slurry Simulant Development Phase 1 Test Results, by C. J. Call, Pacific Northwest Laboratory, Richland, Washington. 
number was 750. For a Reynolds number this large, dissipation by secondary flows in the coiled tubing should be a factor. It is important to note that the capillary rheometer was designed to measure fluids with viscosities in the range of 1 to $100 \mathrm{~Pa}^{*} \mathrm{~s}(100$ to $10,000 \mathrm{cP}$ ). For fluids with viscosities in this range, inertial effects should be negligible; the measurements of the $0.68 \mathrm{~Pa}^{*} \mathrm{~s}$ glycerol/water mixture confirm this. 


\subsection{Results and Discussion}

The viscosity as a function of shear rate for slurries with and without bubbles is shown in Figure 4.1. The pressure and flow data used to calculate these viscosities are given in Appendix C. These slurries all had $50 \mathrm{vol} \%$ glass beads suspended in the $80 \mathrm{wt} \%$ glycerol in water mixture. The viscosity data without bubbles show a weakly shear thinning fluid, except at the lowest shear rate. At a shear rate of $5 \mathrm{~s}^{-1}$, the ratio of the slurry viscosity $\left(1 \mathrm{~Pa}^{*} \mathrm{~s}\right)$ to the viscosity of the suspending fluid $\left(0.068 \mathrm{~Pa}^{*} \mathrm{~s}\right)$ is about 15 . This increase in viscosity because of the particles agrees fairly well with the theoretically predicted value of 11.6 given in Figure 2.1 for a 50 vol\% slurry.

Data collected for bubbly slurries are also shown in Figure 4.1. The viscosity of the slurry with 25 vol\% gas is about four-fold greater than the bubble-free slurry at shear rates below about $5 \mathrm{~s}^{-1}$. The combined increase in viscosity caused by bubbles and particles is about 50 -fold at a shear rate of $5 \mathrm{~s}^{-1}$, although the magnitude of the increase depends on the shear rate. The theoretical result, given by Equation 5 and plotted in Figure 2.1, predicts a 65-fold increase in viscosity for this slurry of 25 vol \% gas and 50 vol\% particles, which again agrees reasonably well with the limited data. In these experiments, observations with a microscope showed that the bubbles were about the same size as the particles. As described in Appendix A (Section A.3), pressure changes affect the gas fraction due to the compressibility of the gas. In the experiment, the largest change in gas volume was about $20 \%$, based on the measured pressures. The second model for the viscosity of a bubbly slurry (yield stress model, Eq. 9) contains an unknown function of gas fraction. Further experimental data are needed to define this function before a comparison can be made with the yield stress model.

The experimental results for the slurry containing 12 vol\% gas, which are also shown in Figure 4.1, show little effect due to the bubbles. Equation 5 predicts that 12 vol\% gas bubbles should increase the viscosity by a factor of 2 . When conducting the experiments with 12 vol $\%$ gas, the bubbles were observed to separate from the slurry within the tubes; this was particularly apparent in the larger-diameter $(1 / 2$ in.) tube and at lower flow rates in both tubes. The coils in the tubing were insufficient to overcome the tendency of the bubbles to rise and collect at the top of the coils. This effect was not observed in experiments with slurry containing $25 \mathrm{vol} \%$ gas. The separation of the gas bubbles makes the accuracy of this data questionable; but these results have been included for completeness.

In general, the presence of bubbles appears to increase the viscosities of the slurries. Based on the limited viscosity data for bubbly slurries, the magnitude of the increase agrees reasonably well with the theoretical results given by Equation 5 and shown in Figure 2.1. Future experimental and theoretical studies are needed to further quantify the effect of bubbles on the viscosities of slurries. These studies should expand upon the results shown here for the effect of gas fraction. The effects of gas-bubble-size solids volume fraction are expected to play roles and should be investigated. In the experiments reported here, only a single particle size (and shape) was investigated, and the suspending fluid was always a $0.68 \mathrm{~Pa}^{*}$ s mixture of glycerol and water. Because DST waste contains a range of particle sizes, and the suspending fluid viscosity varies with both temperature and composition, future studies should investigate the effects of particle size, particle shape, and suspending fluid viscosity. 


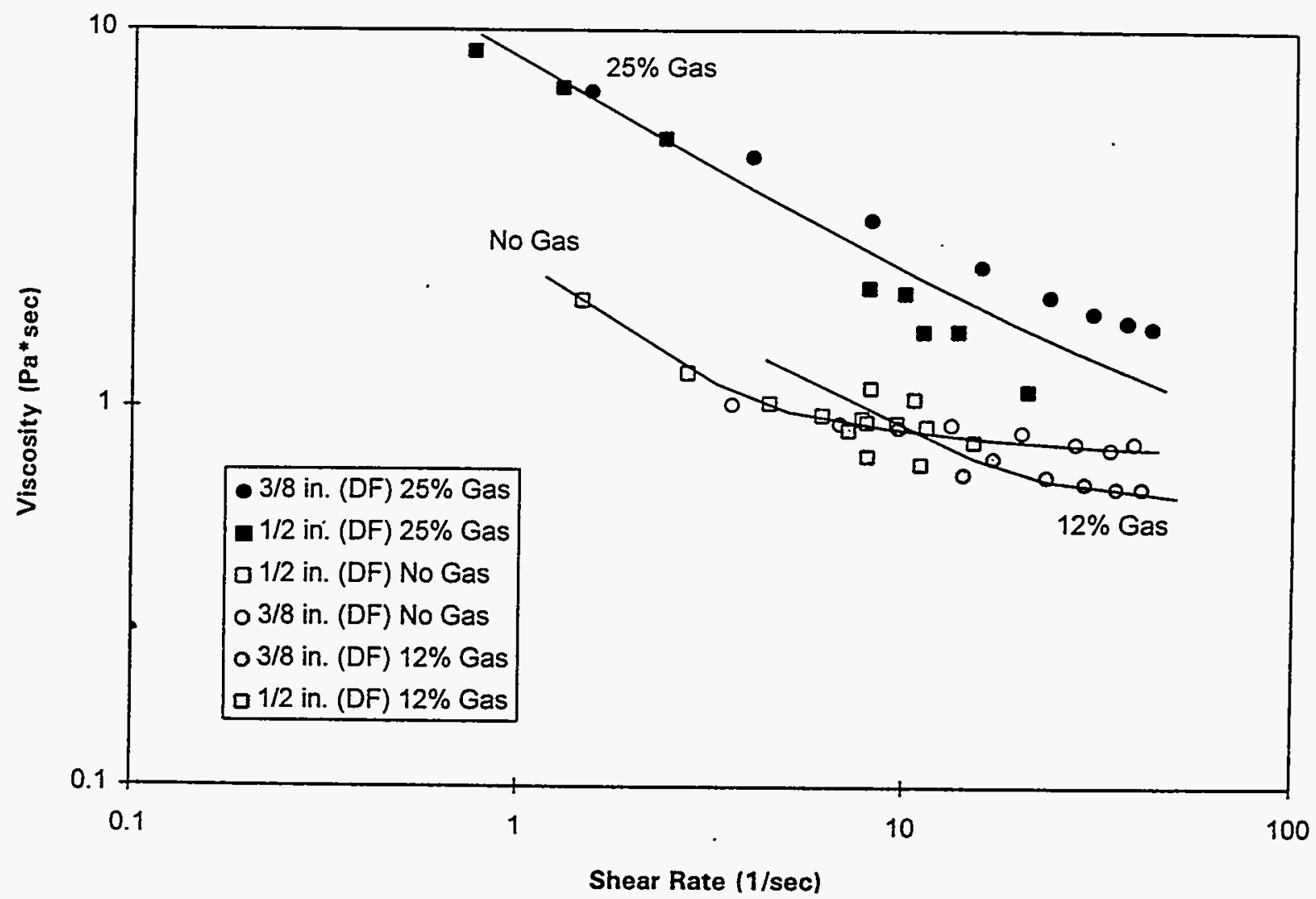

Figure 4.1. Viscosities of Slurries with and Without Bubbles (These slurries all had a 50 vol\% fraction of 90 micron glass beads, and the suspending fluid was a glycerol/water mixture with a viscosity of $0.068 \mathrm{~Pa}^{*} \mathrm{~s}$ ) 


\subsection{Conclusions}

The retention of flammable gases and the episodic release of these gases are critical safety concerns for double-shell tanks containing waste slurries. The rheologic behavior of the waste, particularly of the settled sludge, is critical to characterizing the tendency of the waste to retain gas bubbles. The presence of gas bubbles is expected to affect the rheology of the sludge, but essentially no literature data are available to assess the effect of these bubbles. Accordingly, the objectives of this study were to develop models for the effect of gas bubbles on the rheology of a particulate slurry and to develop a theoretical basis for interpreting experimental data on the rheology of bubbly slurries.

Two models have been proposed to account for the effect of gas bubbles on the viscosities of particulate slurries. In the first method, bubbles are treated as solid particles that fit in the spaces between the actual particles. In the second approach, the bubbles contribute a yield stress to the slurry, and the viscosity of the bubbly slurry is a combination of a shear thinning term due to particles and an additional yield stress due to the bubbles. In both cases, the models predict an increase in viscosity due to the bubbles.

To quantify experimentally the effect of bubbles on sludge properties, a capillary rheometer suitable for studying bubbly slurries was developed. A detailed analysis of capillary rheometry for bubbly slurries that possess a yield stress and that slip at the capillary wall shows that the method is valid for bubbly slurries.

Experimental results have been obtained for bubbly slurries, slurries without bubbles, and simple Newtonian fluids, including water and glycerol/water mixtures. The experiments with Newtonian fluids were conducted to validate the new apparatus. The measurements on slurries were conducted to collect baseline data. Studies with bubbly slurries used the same slurry as without bubbles to highlight the effect of the bubbles.

For the slurry measurements, 50 vol\% of glass beads (90 microns) increased the viscosity $15-$ fold over the same glycerol/water mixture without particles. For experiments with bubbles, 50 vol\% of glass beads ( 90 microns) were again mixed with $50 \mathrm{vol} \%$ of a fluid, but the fluid was a mixture of gas bubbles, glycerol, and water. Bubble loadings of $12 \mathrm{vol} \%$ and $25 \mathrm{vol} \%$ were investigated. The bubbles were about the same size as the particles, based on observations with a microscope. The bubbles increased the viscosity of the slurry about four-fold for a bubble loading of 25 vol\%.

Future experimental studies will seek to better control the bubble size and bubble volume fraction and will also seek to cover a broader range of bubble sizes and volume fractions. Future theoretical investigations will focus on developing improved models for the role of bubble size and volume fraction on the viscosities of bubbly slurries. 


\subsection{References}

Allemann, R. T., Z. I. Antoniak, J. R. Friley, C. E. Haines, L. M. Liljegren, and S. Somasundaram. 1990a. Mechanistic Analysis of Double-Shell Tank Gas Release--Progress Report, November. PNL-7657, Pacific Northwest Laboratory, Richland, Washington.

Allemann, R. T., Z. I. Antoniak, J. R. Friley, C. E. Haines, L. M. Liljegren, and S. Somasundaram. 1990b. Collection and Analysis of Existing Data for Waste Tank Mechanistic Analysis-Progress Report, December. PNL-7658, Pacific Northwest Laboratory, Richland, Washington.

Allemann, R. T., Z. I. Antoniak, L. L. Eyler, and L. M. Liljegren. Conceptual Models for Waste Tank Mechanistic Analysis-Status Report, January. 1991. PNL-8011, Pacific Northwest Laboratory, Richland, Washington.

Allemann, R. T., T. M. Burke, D. A. Reynolds, and D. E. Simpson. 1993. Assessment of Gas Accumulation and Retention - Tank 241-SY-101. WHC-EP-0576, Westinghouse Hanford Company, Richland, Washington.

Barnes, H. A., J. F. Hutton, and K. Walters. 1989. An Introduction to Rheology. Elsevier, New York.

Bryan, S. A., L. R. Pederson, J. L. Ryan, R. D. Scheele, and J. M. Tingey. 1992. Slurry Growth, Gas Retention, and Flammable Gas Generation by Hanford Radioactive Waste Tanks: Synthetic Waste Studies, FY 1991. PNL-8169, Pacific Northwest Laboratory, Richland, Washington.

Denn, M. M. 1980. Process Fluid Mechanics. Prentice-Hall, Englewood Cliffs, New Jersey, p. 369.

Hall, M. N. 1993. Tank 101-SY Hydrogen Mitigation by Low Frequency Vibration - Rheological Analysis and Feasibility Assessment. WHC-SD-WM-ER-164, Westinghouse Hanford Company, Richland, Washington.

Harris, P. C., and V. G. Reidenbach. May 1987. "High-Temperature Rheological Study of Foam Fracturing Fluids." J. of Petroleum Tech., pp. 613-619.

Heath, W. O. 1987. Development of an In Situ Method to Define the Rheological Properties of Slurries and Sludges Stored in Underground Tanks. PNL-6083, Pacific Northwest Laboratory, Richland, Washington.

Herting, D. L. 1991. Laboratory Characterization of Samples Taken in May 1991 from Hanford Waste Tank 241-SY-101. WHC-SD-WM-DTR-024 Rev. 0, pp. 3-5. Westinghouse Hanford Company, Richland, Washington.

Kahn, S. A., C. A. Schnepper, and R. C. Armstrong. 1988. "Foam Rheology: III Measurement of Shear Flow Properties." J. Rheology, 32(1): 69-92. 
Kraynik, A. M. 1988. "Foam Flows." Ann. Rev. Fluid Mech., 20, pp. 235-357.

Mahoney, L. A., G. Terrones, and L. L. Eyler. 1994. Modeling and Analysis of ORNL Horizontal Storage Tank Mobilization and Mixing, Appendix A. PNL-9961, Pacific Northwest Laboratory, Richland, Washington.

Nguyen, Q. D., and D. V. Boger. 1983. "Yield Stress measurements for Concentrated Suspensions." J. Rheology, 26(4): 321-349.

Pal, R., and E. Rhodes. 1989. "Viscosity/Concentration Relationships for Emulsions." J. Rheology, 33(7): 1021-1045.

Patton, J. T., S. T. Holbrook, and W. Hsu. June 1983. "Rheology of Mobility-Control Foams." Society of Petr. Engr. J., pp. 456-460.

Princen, H. M. 1985. "Rheology of Foams and Highly Concentrated Emulsions. II. Experimental Study of the Yield Stress and Wall Effects for Concentrated Oil-in-Water Emulsions." J. Coll. Inter. Sci., 105, pp. 150-171.

Reidenbach, V. G., P. C. Harris, Y. N. Lee, and D. L. Lord. January 1986. "Rheological Study of Foam Fracturing Fluids Using Nitrogen and Carbon Dioxide." Society of Petr. Engr. Production Engineering, pp. 31-41.

Reynolds, D. A. 1992. Tank 101-SY Window C Core Sample Results and Interpretation. WHC-EP0589, Westinghouse Hanford Company, Richland, Washington.

Tennant, R. A., E. C. Sams, and J. P. Piccola, Jr. 1993. Simulation and Rheological Analysis of Hanford Tank 241-SY-101. LA-UR-93-3800, Los Alamos National Laboratory, Los Alamos, New Mexico.

Thondavadi, N. N. 1983. Flow properties of Foam with and without Solid Particles. Ph.D. Thesis University of Cincinnati.

Trent, D. S., and T. E. Michener. 1993. Numerical Simulation of Jet Mixing Concepts in Tank 241SY-101. PNL-8559, Pacific Northwest Laboratory, Richland, Washington.

Yoshimura, A. S., R. K. Prud'homme, H. M. Princen and A. D. Kiss. 1987. "A Comparison of Techniques for Measuring Yield Stresses." J. Rheology, 31(8), pp. 699-710. 


\section{Appendix A}

\section{Capillary Rheometry Theory}




\section{Appendix A}

\section{Capillary Rheometry Theory}

In the main report, Figure 2.1 shows the situation of a non-Newtonian fluid with a yield stress flowing through a cylindrical capillary where the fluid slips along the capillary wall. The capillary rheometry method allows the viscosity of any time-independent fluid, such as the one depicted in the figure, to be obtained from flow rate pressure drop data. Thus thixotropic suspensions are excluded in general from this analysis. The traditional theoretical analysis begins with an integral equation for flow rate, changes variables from radial position to shear stress, and then differentiates the resulting integral equation with respect to the wall shear stress. The resulting equations give viscosity as a function of shear rate without assuming any model for the fluid. This derivation is given here in detail to determine if the presence of gas bubbles limits the application of the method in any way.

\section{A.1 Theory}

The derivation of the equations begins with the momentum equation (Denn 1980):

$$
-\frac{\partial P}{\partial z}+\frac{1}{r} \frac{d}{d r}\left(r \tau_{r}\right)=0
$$

where the coordinates and variables are defined in Figure 2.1 and $\tau_{\pi z}$ is the shear stress. Integrating once gives

$$
\tau_{r z}=\frac{r}{2}\left(\frac{\Delta P}{L}\right)
$$

The shear stress at the capillary wall, $\tau_{w}$, which by convention is positive, becomes

$$
\tau_{w}=\frac{R}{2}\left(\frac{-\Delta P}{L}\right)
$$

The remainder of the analysis involves calculating the shear rate at the wall, which will then be used with Equation A.3. 
The shear stress is related to viscosity as follows:

$$
\tau_{r z}=\eta \frac{d v_{z}}{d r}
$$

Combining with Equation A.2 gives

$$
\eta \frac{d v_{z}}{d r}=\frac{r}{2}\left(\frac{\Delta P}{L}\right)
$$

Rearranging and integrating over the capillary cross section gives

$$
\int_{0}^{R} \pi r^{2} d v_{z}=\left(\frac{\Delta P}{L}\right) \int_{0}^{R} \frac{\pi r^{3}}{2 \eta} d r
$$

The left side of Equation A.6 can be integrated by parts and rearranged to give

$$
Q=\pi R^{2} V_{w}+\frac{2 \tau_{w}}{R} \int_{0}^{R} \frac{\pi r^{3}}{2 \eta(r)} d r
$$

where $Q$ is the volumetric flow through the capillary. The first term on the right hand side accounts for slip at the capillary wall where $V_{w}$ is the slip velocity. This is a general result valid for any timeindependent fluid including fluids with a yield stress.

The next step is to change variables from $r$ to $\tau_{\mathrm{w}}$. Combining Equations A.2 and A.3 gives the following relationship between $r$ and the wall shear stress:

$$
\begin{gathered}
r=-R \frac{\tau^{\tau} z}{\tau_{w}} \\
d r=\frac{-R}{\tau_{w}} d \tau_{r}
\end{gathered}
$$


Substituting these expressions into Equation A.7 and rearranging gives

$$
Q=\pi R^{2} V_{w}\left(\tau_{w}\right)+\frac{\pi R^{3}}{\tau_{w}^{3}} \int_{-\tau_{y}}^{-\tau_{w}} \frac{\cdot \tau_{r z}^{3}}{\eta\left(\tau_{r z}\right)} d \tau_{r}
$$

As recommended by Nguyen and Boger (1992), the lower limit of the integration is evaluated at the yield stress for the fluid $\tau_{y}$. This result is general and applies to fluids without a yield stress.

The final step involves differentiating Equation A.10 with respect to $\tau_{\mathrm{w}}$, the wall shear stress. Applying the chain and Leibnitz rules to Equation A.10 gives the following term-by-term result:

$$
\begin{gathered}
\frac{d Q}{d \tau_{w}}=\pi R^{2} \frac{d V_{w}\left(\tau_{w}\right)}{d \tau_{w}}-\frac{3 \pi R^{3}}{\tau_{w}^{4}}\left[\int_{-\tau_{y}}^{-\tau_{w}} \frac{\tau_{r z}^{3}}{\eta\left(\tau_{r z}\right)} d \tau_{r z}\right] \\
+\frac{\pi R^{3}}{\tau_{w}^{3}}\left[\int_{-\tau_{y}}^{-\tau_{w}} \frac{d}{d \tau_{w}}\left[\frac{\tau_{r z}^{3}}{\eta\left(\tau_{r}\right)} d \tau_{r z}\right]+\frac{\tau_{r z}^{3}}{\eta\left(\tau_{r z}\right)}\left|\frac{d\left(-\tau_{w}\right)}{d \tau_{w}}-\frac{\tau_{r z}^{3}}{\eta\left(\tau_{r z}\right)}\right|_{\tau_{y}} \frac{d\left(\tau_{y}\right)}{d \tau_{w}}\right)
\end{gathered}
$$

Dropping terms that are identically zero gives

$$
\frac{d Q}{d \tau_{w}}=\frac{\pi R^{3}}{\eta\left(\tau_{w}\right)}-\frac{3 Q}{\tau_{w}}+\frac{3 \pi R^{2} V_{w}}{\tau_{w}}+\pi R^{2} \frac{d V_{w}}{d \tau_{w}}
$$

The first two terms on the right side are the conventional terms, and the final two terms on the right hand side are corrections for wall slip. By definition, the shear rate at the capillary wall, $\dot{\gamma}_{w}$ is related to the shear stress and viscosity at the wall, $w$, as follows:

$$
\dot{\gamma}_{w}=\frac{\tau_{w}}{\eta_{w}}
$$

Using this definition and rearranging Equation A.12 gives the final result for wall shear rate:

$$
\dot{\gamma}_{w}=\frac{4\left(Q-\pi R^{2} V_{w}\right)}{\pi R^{3}}\left(\frac{3}{4}+\frac{1}{4} \frac{d \ln \left(Q-\pi R^{2} V_{w}\right)}{d \ln \tau_{w}}\right)
$$


This result, combined with Equation A.13, specifies how flow rate pressure drop data give the viscosity as a function of shear rate.

It is common to define the true flow of the material, $Q_{t}$, as follows:

$$
Q=Q_{t}+\pi R^{2} V_{w}
$$

It is now clear that the flow terms in Equation 24 are grouped together to give $Q_{r}$.

\section{A.2 Correction for Wall Slip}

The original method of correcting capillary flow data for wall slip was proposed by Mooney (1931), and this approach has been extended recently to analyze wall slip effects in Couette and parallel Disk geometries for both steady and oscillatory shear measurements (Yoshimura and Prud'homme 1988a, b). Yilmazer and Kalyon (1989) have discussed the effect of wall slip in concentrated suspensions and conclude that slip effects dominate the flow and that true flow and deformation may be overshadowed by slip at the walls.

The analysis for wall slip begins with Equation A.10 expressed in terms of the average velocity $\langle V\rangle$ :

$$
\frac{8<\nu>}{D}=\frac{8}{D} V_{w}\left(\tau_{w}\right)+\frac{4}{\tau_{w}^{3}} \int_{-\tau_{y}}^{-\tau_{w}} \frac{\tau_{r z}^{3}}{\eta\left(\tau_{r z}\right)} d \tau_{r z}
$$

This result shows that a plot of $(8<v>/ D)$ versus $8 / D$ at constant wall shear stress should give a straight line with slope of $V_{w}$. The slopes must be determined for a range of wall shear stresses to quantify wall slip and correct the actual flow to the true flow in Equation A.14.

A further modification is to assume a model for the wall slip. One model suggested in the literature is given below:

$$
V_{W}=\epsilon\left(\frac{2}{D}\right)^{a} \tau_{w}
$$

This model includes a diameter dependent slip velocity. The appropriate data analysis plots $(8<v>/ D)$ versus $1 / D^{(l+a)}$ at constant wall shear stress. The slope of the lines at each $\tau_{\mathrm{w}}$ equals $2^{\mathrm{a}+2} \epsilon \tau_{\mathrm{w}}$, which then gives the wall slip parameter $\epsilon$. The parameter $a$ is adjusted to give the best fit to the data. Some experimental evidence (Yilmazer and Kalyon 1989) suggests that the slip velocity is independent of capillary diameter, giving the simplest case of $a=0$ in Equation A.17. 


\section{A.3 Compressibility}

When the bubbly slurry flows through the capillary, the gas bubbles will expand as the pressure decreases along the capillary. This affects both the gas fraction and the flow of the bubbly slurry. The amount of gas expansion can be determined assuming an ideal gas. The ratio of the gas volume exiting, $V_{2}$, and entering, $V_{1}$, the capillary is given by

$$
\frac{V_{2}}{V_{1}}=1+\frac{\Delta P}{P_{2}}
$$

where $P_{2}$ is the pressure at the capillary exit, and $\Delta P$ is pressure difference from the inlet to the exit of the capillary. Gas expansion effects can be minimized by maintaining a small $\Delta P$ across the capillary or by increasing the pressure.

\section{A.4 References}

Mooney, M. 1931. J. Rheology, 2, p. 210.

Nguyen, Q. D., and D. V. Boger. 1992. "Measuring the Flow Properties of Yield Stress Fluids." Ann. Rev. Fluid Mech., 24, pp. 47-88.

Yilmazer, U., and D. M. Kalyon. 1989. "Slip Effects in Capillary and Parallel Disk Torsional Flows of Highly Filled Suspensions." J. Rheology, 33(8): 1197-1212.

Yoshimura, A. S., and R. K. Prud'homme. 1988a. "Wall Slip Corrections for Couette and Parallel Disk Viscometers." J. Rheology, 32(1): 53-67.

Yoshimura, A. S., and R. K. Prud'homme. 1988b. "Wall Slip Effects on Dynamic Oscillatory Measurements." J. Rheology, 32(6): 575-584. 
Appendix B

Examples of Capillary Rheometry Data Analysis 


\section{Appendix B}

\section{Examples of Capillary Rheometry Data Analysis}

To determine viscosity from flow rate and pressure-drop data, the results given by Equations 11 (A.14), 12 (A.3) and 13 (A.13) are used in conjunction with wall slip correction. To determine the derivative of the flow $(Q)$ versus pressure drop (as $\tau_{w}$ ) data for use in Equation 11, a numerical algorithm was used rather than plotting the data. A three-point central difference relation, for unequally spaced data, was derived to calculate the slopes at each point. The derivation followed the standard method of using Taylor series expansions to determine the difference expressions (Lapidus 1962). For a set of data of $\left(f_{i}, x_{i}\right)$, the slope $d f / d x$ at $x_{i}$ is given as follows:

$$
\frac{d f\left(x_{i}\right)}{d x}=\frac{\frac{h_{i}}{h_{i+1}} f_{i+1}+\left[\frac{h_{i+1}}{h_{i}}-\frac{h_{i}}{h_{i+1}}\right] f_{i}-\frac{h_{i+1}}{h_{i}} f_{i-1}}{h_{i}+h_{i+1}}
$$

where $h_{i} \quad=x_{i}-x_{i-1}$

$h_{i+1}=x_{i+1}-x_{i}$

Equation B.1 reduces to the standard three-point central difference relation for equally spaced data (Lapidus 1962). When analyzing real (noisy) data using this technique, care must be taken, because point-by-point derivatives of noisy data can be misleading. Tests with simulated noisy data indicate that the central difference differentiation works reasonable well. A second approach to reducing the effect of noise is to apply a least-squares method to curve-fit the data with a polynomial. For data spanning a wide range of shear rates, the least-squares method should be applied on a local level (such as point-by-point).

To test the numerical technique, we have calculated flow rate as a function of pressure drop for a variety of non-Newtonian fluids. We will refer to the results of these calculations as simulated data. We then use the numerical technique for calculating the derivatives. The fluid viscosity as a function of shear rate is then determined with Equations 11 (A.14), 12 (A.3) and 13 (A.13). As an example of our test calculations, we will show the results for a Bingham-Power Law (BPL) model, which is the simplest expression combining shear thinning/thickening and a yield stress. Suspensions and slurries are generally shear thinning materials at lower shear rates. With the addition of bubbles, slurries are even more likely to have yield stresses that will affect the flow properties. The derivation of the flow pressure drop relation for a BPL fluid model is given in Equation B.2. for fluids:

The BPL viscosity relation is a combination of the Power Law and Bingham Plastic models 


$$
\eta=k\left|\frac{d v_{z}}{d r}\right|^{n-1}+\tau_{0}\left|\frac{d v_{z}}{d r}\right|^{-1}
$$

The shear stress expression for the viscosity given by Equation B.2 is

$$
\tau_{r z}=-k\left|\frac{d v_{z}}{d r}\right|^{n}+\tau_{0}=\frac{-\Delta P r}{2 L}
$$

Combining Equation B.3 for shear stress with the Cauchy momentum equation (Bird et al. 1960 ), assuming no wall slip, and solving the resulting differential equation gives the following velocity profile expression:

$$
V_{z}=\frac{n+1}{n}\left[\frac{2 k l}{\Delta P}\right]\left[\left(\frac{\tau_{o}}{k}+\frac{\Delta P R}{2 k l}\right)^{\frac{n+1}{n}}-\left(\frac{\tau_{o}}{k}+\frac{\Delta P r}{2 k l}\right)^{\frac{n+1}{n}}\right]
$$

Finally, integrating the velocity profile over the cross section of the cylindrical tube gives the volumetric flow rate:

$$
\begin{gathered}
Q=2 \pi\left(\frac{n}{n+1}\right)\left(\frac{2 k l}{\Delta P}\right) * \\
\frac{R^{2}}{2}\left[\frac{\tau_{o}}{k}+\frac{\Delta P R}{2 k l}\right]^{\frac{n+1}{n}}-n\left(\frac{2 k l}{\Delta P}\right)^{2}\left[\frac{\left(\frac{\tau_{o}}{k}+\frac{\Delta P R}{2 k l}\right)^{\frac{3 n+1}{n}}}{3 n+1}-\frac{\left(\frac{\tau_{o}}{k}\right)\left(\frac{\tau_{o}}{k}+\frac{\Delta P R}{2 k l}\right)^{\frac{2 n+1}{n}}}{2 n+1}\right]
\end{gathered}
$$

Equation B.5 includes both the Power Law and Bingham Plastic models; Equation B.5 correctly reduces to a Power Law model when the yield stress is zero (Equation B.6), and simplifies to the correct Bingham fluid expression when the power law index is set to 1 (Equation B.7). 


$$
\begin{gathered}
Q=\pi\left(\frac{n}{3 n+1}\right) R^{\frac{3 n+1}{n}}\left(\frac{\Delta P}{2 k L}\right)^{\frac{1}{n}} \\
Q=\frac{\pi \Delta P R^{4}}{8 k l}\left[1-\frac{4}{3}\left(\frac{r_{0}}{R}\right)+\frac{1}{3}\left(\frac{r_{0}}{R}\right)^{4}\right]
\end{gathered}
$$

The capillary rheometry data analysis technique was tested with the BPL model. Figure B.1 shows simulated flow and pressure drop data for a Bingham-Power Law fluid; the symbols represent the simulated data. The slope of these data gives the wall shear rate by application of A.14, and then the viscosity is calculated with Equation A.13. Figure B.2 shows the viscosity calculated from the simulated data (symbols) and the exact result. As expected, the simulated data and exact result agree.

\section{References}

Bird, R. B., W. E. Stewart, and E. N. Lightfoot. 1960. Transport Phenomena. John Wiley \& Sons, New York.

Lapidus, L. 1962. Digital Computation for Chemical Engineers. McGraw-Hill, New York. 


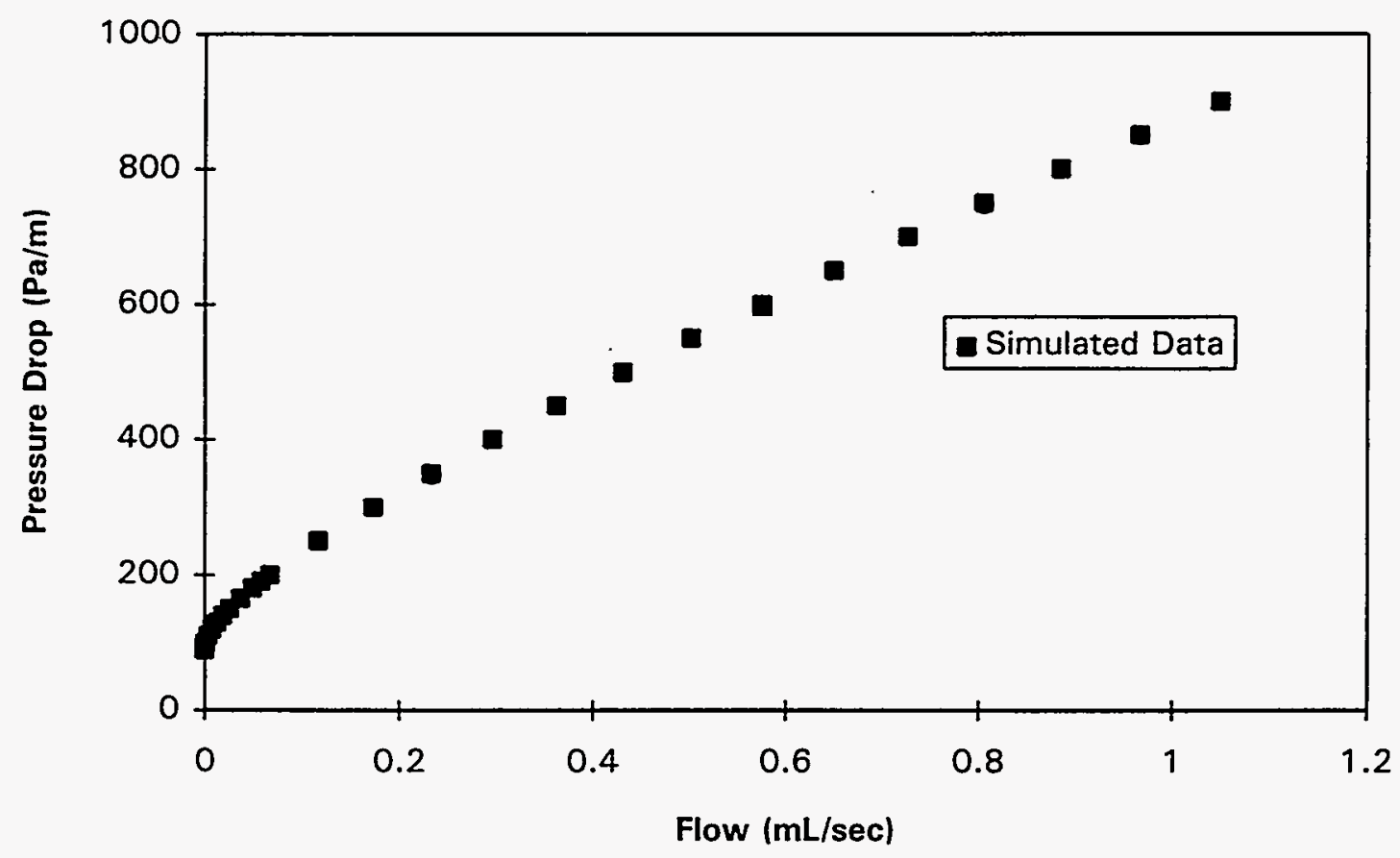

Figure B.1. Exact Theoretical Flow Data for a Bingham Power-Law Fluid

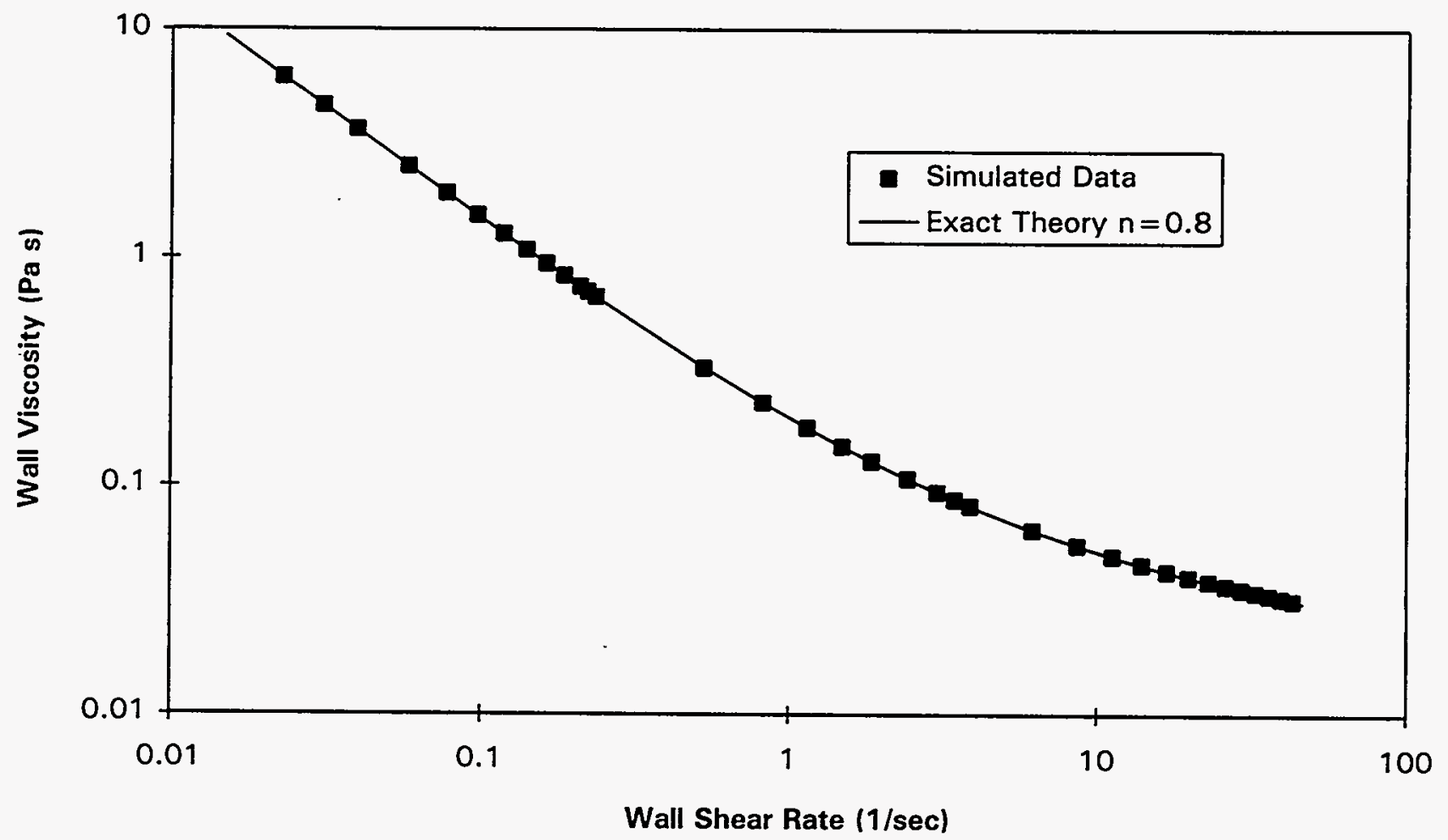

Figure B.2 Viscosity and Wall Shear Rate for a Bingham Power-Law Fluid

B. 4 


\section{Appendix C}

\section{Pressure and Flow Data}


material, CWA $\$ 404$ and 40 CFR 230.10(b) may be applicable. If any proposed actions impact state-listed endangered or threatened animal species, the Tennessee Non-Game and Endangered or Threatened Wildlife Species Conservation Act of 1974 (TCA 70-8-101 et seq.) may be applicable. The prohibitions of the Tennessee Rare Plant Protection and Conservation Act of 1985 (TCA 11-26-201 et seq.) do not apply to a landowner, lessee, or other person entitled to possession of the land on which the species is located (TCA 11-26-209). This also includes managers in the case of publicly owned land and those with written permission of the landowner or manager (TCA 11-26-209). These exclusions would apparently apply to ORNL. However, the purpose of the statute to protect and preserve rare plants should be considered guidance for any RAs on the reservation.

\subsubsection{Historic Sites and Archaeological Findings}

ORR, as well as the surrounding region, is rich in both archaeological and historic resources. ${ }^{22}$ Although there have not been complete and exhaustive archaeological or historical surveys of the reservation, there have been a number of studies over the years, all indicating the presence of abundant resources on and around the reservation. These surveys are summarized in Vol. 3 of the Resource Management Plan for the $U$. S. Department of Energy Oak Ridge Reservation ${ }^{22}$ which also includes a list and descriptions of most of the documented sites. Eight archaeological sites were identified at ORNL; of the eight, it was recommended that three (40RE27, 40RE101, and 40RE1-32) be extensively tested and possibly excavated if threatened by construction or remedial activities. ${ }^{22}$ None of the surveys done is recent, however, nor have they covered all of the specific sites where RAs may be planned or contemplated. Several laws require that such information be obtained and documented if there is ample reason to suspect the presence of these resources [Archaeological and Historic Preservation Act (16 USC 469a-c); Archaeological Resources Recovery Act of 1979 (16 USC 470aa-ll)].

The National Register of Historic Places lists the Graphite Reactor located at ORNL as an historic site, and the National Historic Preservation Act (16 USC 470a-w) mandates identification of cultural resources eligible for the National Register of Historic Places (36 CFR 60) or the National Historic Landmark Program (36 CFR 65).

If any RA is undertaken which would cause irreparable harm, loss, or destruction to any historic or archaeological site, the provisions of the Archaeological Resources Recovery Act (16 USC 470aa-11), 43 CFR 7, the Archaeological and Historic Preservation Act (16 USC 469a-c) and 40 CFR 6.301 may be legally applicable. The provisions of this latter statute would also apply to the Graphite Reactor along with EO 11593, 40 CFR 6.301 and 36 CFR 800 et seq.

Lastly, there are a number of cemeteries located on ORR which predate the acquisition of the property by the government. Any RAs that affect these cemeteries would be subject to the provisions of the Tennessee Cemetery Protection Act (TCA 46-1-101 et seq.), which prohibits their destruction or degradation. 
, 


\section{Appendix C}

\section{Pressure and Flow Data}

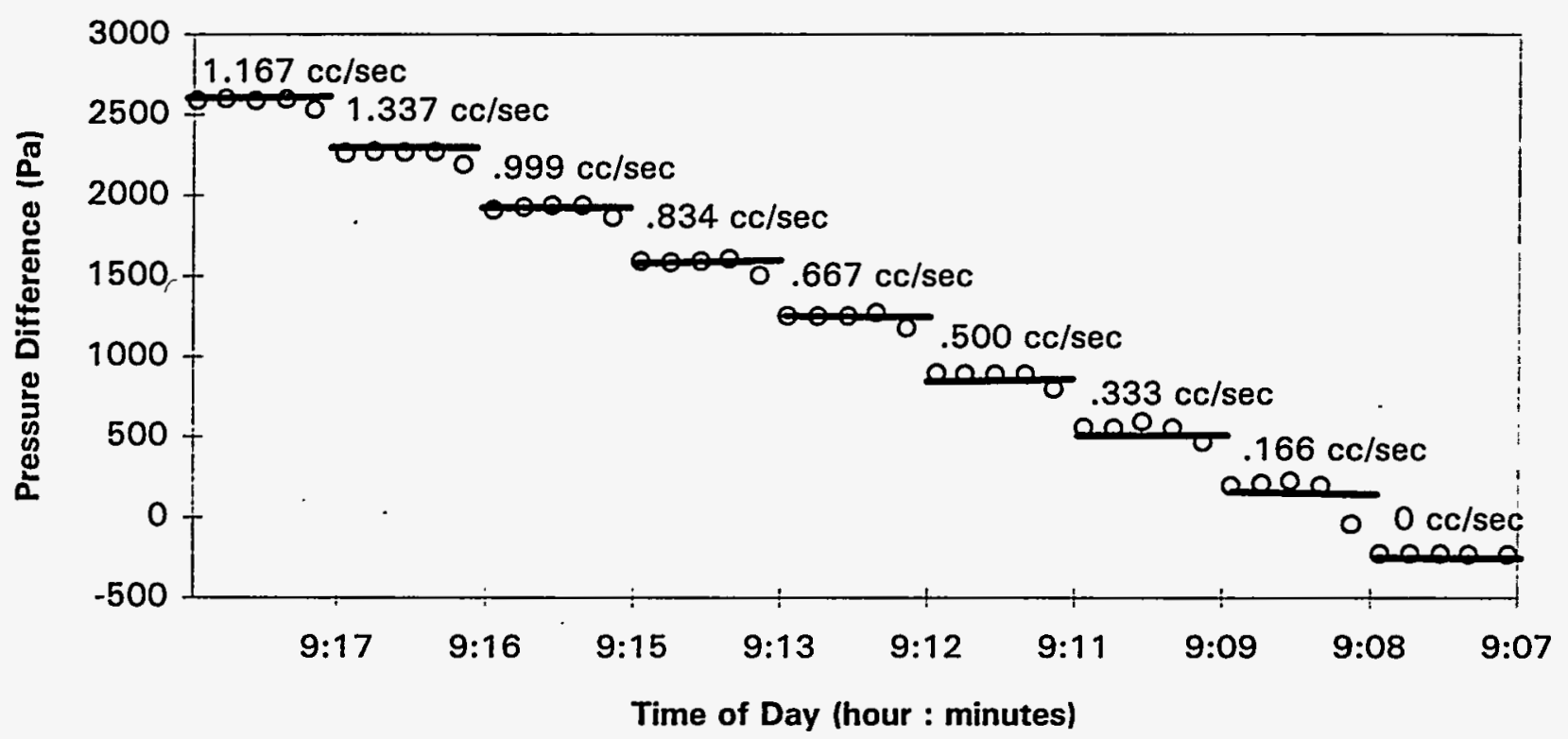

Figure C.1. Pressure Drop at Each Measured Flow for Mixture of $80 \mathrm{wt} \%$ Glycerol in $20 \mathrm{wt} \%$ Water [Tube was $133 \mathrm{~cm}$ long with an internal diameter of $0.66 \mathrm{~cm}(3 / 8 \mathrm{in}$. nominal)]

Table C.1. Capillary Rheometer Data for $80 \%$ Glycerol and $20 \%$ Water [133 cm long tube with $.66 \mathrm{~cm}$ internal diameter ( $3 / 8$ in. tube)]

\begin{tabular}{||l|l|l|l||}
\hline Pressure Drop (Pa) & Flow Rate (cc/sec) & Shear Rate $(1 / \mathrm{sec})$ & Viscosity $(\mathrm{Pa} * \mathrm{sec})$ \\
\hline \hline-228.452 & 0 & & \\
\hline 204.9824 & .166636 & & \\
\hline 553.6754 & .333272 & 11.22704 & .061091 \\
\hline 890.5151 & .500061 & 17.04083 & .064734 \\
\hline 1251.498 & .666135 & 22.95517 & .067536 \\
\hline 1594.767 & .833487 & 29.11122 & .067861 \\
\hline 1928.096 & .999662 & 35.03093 & .068181 \\
\hline 2267.751 & 1.167219 & 41.01146 & .068497 \\
\hline 2595.789 & 1.33186 & & \\
\hline
\end{tabular}

C.1 


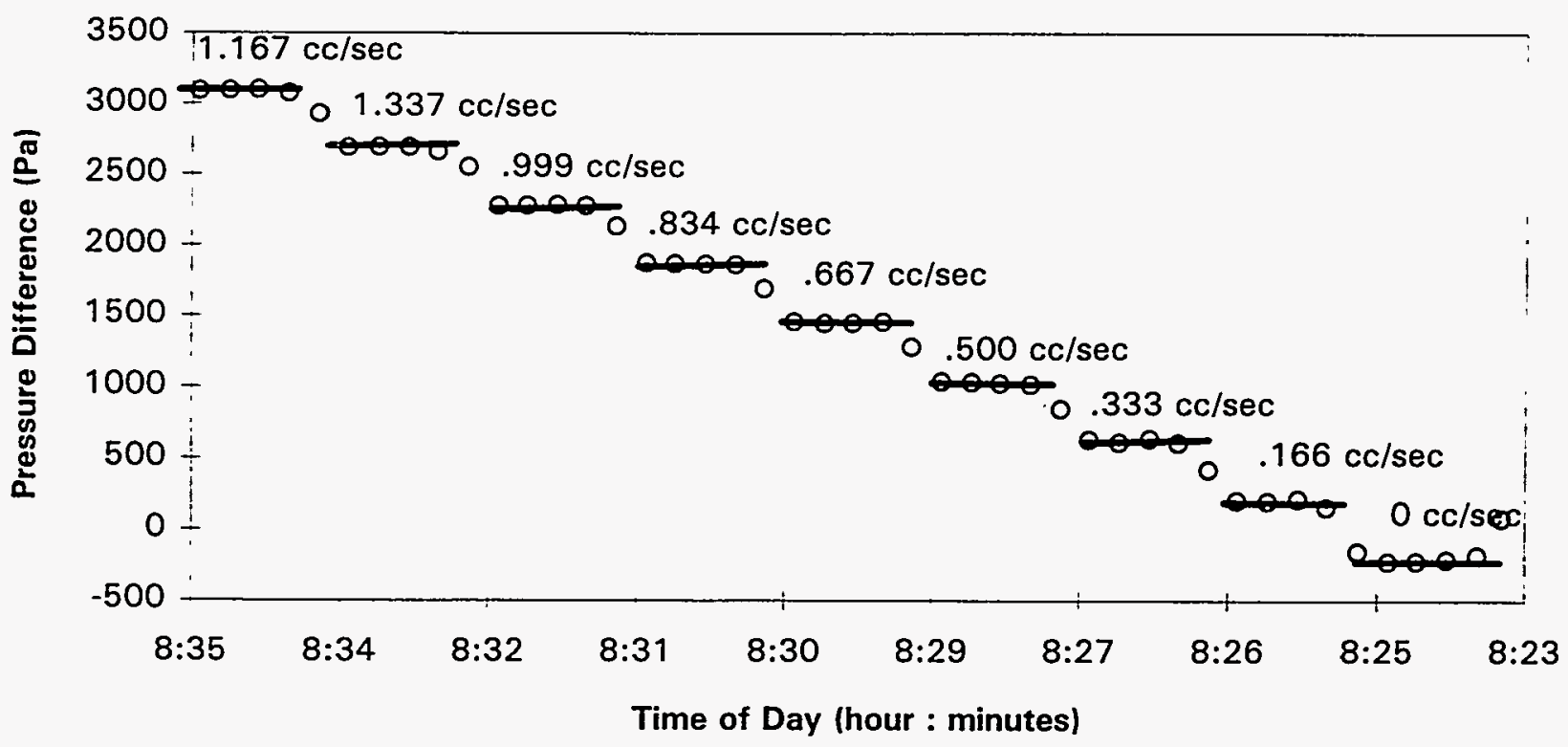

Figure C.2. Pressure Drop at Each Measured Flow for a Mixture of $80 \mathrm{wt} \%$ Glycerol in $20 \mathrm{wt} \%$ Water [Tube was $702 \mathrm{~cm}$ long with an internal diameter of $0.96 \mathrm{~cm}(1 / 2 \mathrm{in}$. nominal)]

Table C.2. Capillary Rheometer Data for $80 \%$ Glycerol and $20 \%$ Water [702 cm long tube with $.96 \mathrm{~cm}$ internal diameter (1/2 in. tube)]

\begin{tabular}{||l|l|l|l||}
\hline Pressure Drop $(\mathrm{Pa})$ & Flow Rate $(\mathrm{cc} / \mathrm{sec})$ & Shear Rate $(1 / \mathrm{sec})$ & Viscosity $\left(\mathrm{Pa}{ }^{*} \mathrm{sec}\right)$ \\
\hline \hline-208.533 & 0 & & \\
\hline 193.6577 & .166483 & & \\
\hline 622.5143 & .333425 & 3.591381 & .059263 \\
\hline 1030.221 & .500368 & 5.504708 & .063987 \\
\hline 1453.769 & .666697 & 7.418316 & .067002 \\
\hline 1868.594 & .833487 & 9.359014 & .068262 \\
\hline 2280.041 & .999049 & 11.31246 & .06891 \\
\hline 2683.853 & 1.167066 & 13.26427 & .0691784 \\
\hline 3090.37 & 1.333395 & & \\
\hline
\end{tabular}

C. 2 


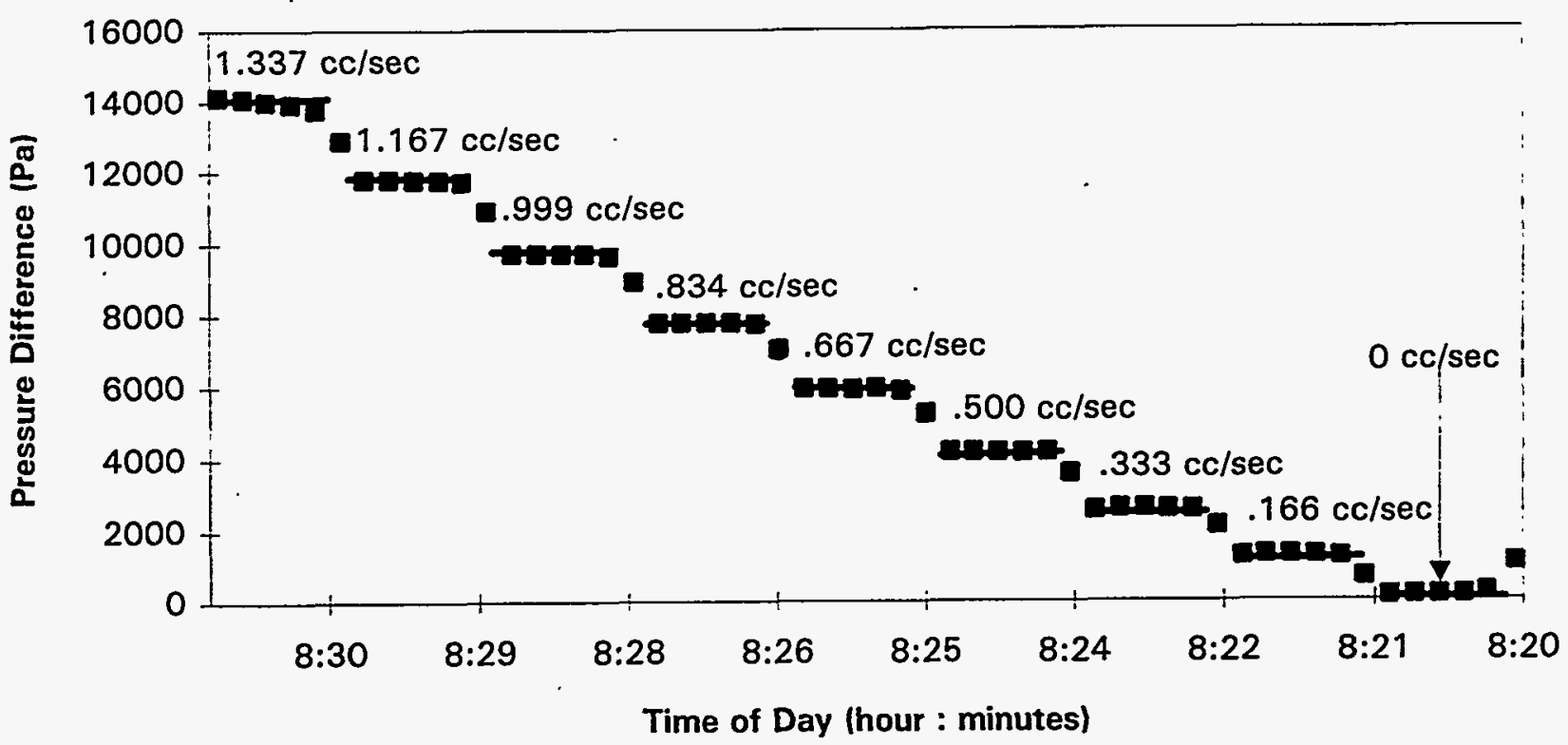

Figure C.3. Pressure Drop at Each Measured Flow for Water in a $306 \mathrm{~cm}$ Long Tube with an Internal Diameter of $0.2 \mathrm{~cm}(1 / 8 \mathrm{in}$.)

Table C.3. Capillary Rheometer Data for Water $[306 \mathrm{~cm}$ long tube with $.20 \mathrm{~cm}$ internal diameter (1/8 in. tube)]

\begin{tabular}{||l|l|l|l||}
\hline Pressure Drop $(\mathrm{Pa})$ & Flow Rate (cc/sec) & Shear Rate $(1 / \mathrm{sec})$ & Viscosity $(\mathrm{Pa}$ *sec) \\
\hline \hline 127.1746 & 0 & & \\
\hline 1269.112 & .166452 & & \\
\hline 2590.418 & .333272 & 413.4596 & .001024 \\
\hline 4182.151 & .499969 & 610.6388 & .001119 \\
\hline 5921.93 & .66728 & 812.0095 & .001192 \\
\hline 7777.61 & .833855 & 1013.359 & .001254 \\
\hline 9702.307 & .999202 & 1212.227 & .001308 \\
\hline 11769.34 & 1.167373 & 1410.99 & .001363 \\
\hline 13976.82 & 1.337139 & & \\
\hline
\end{tabular}




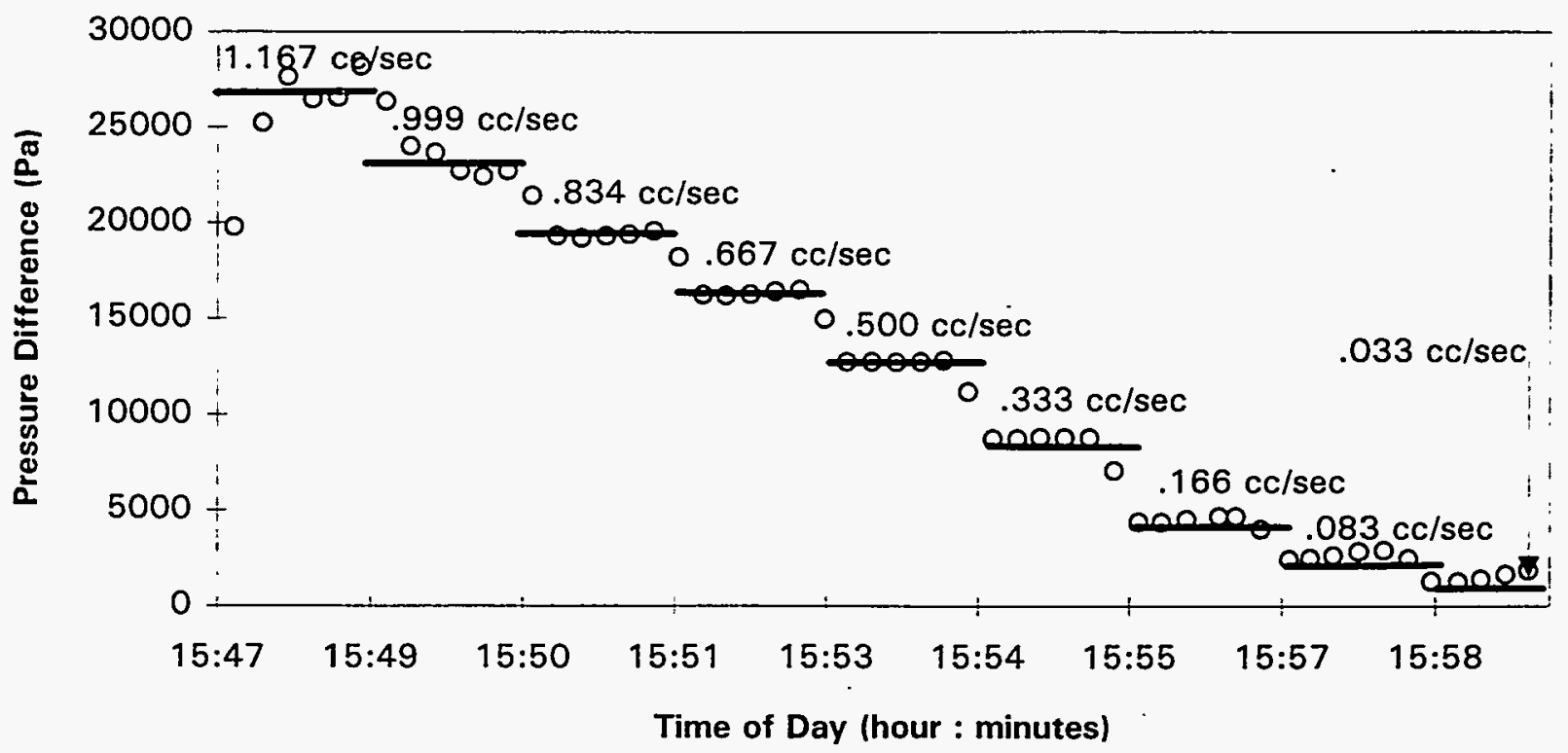

Figure C.4. Pressure Drop at Each Measured Flow for a Slurry Containing 50 vol\% Glass Beads and $50 \mathrm{vol} \%$ of a Mixture of $80 \mathrm{wt} \%$ Glycerol in $20 \mathrm{wt} \%$ Water [Tube was $133 \mathrm{~cm}$ long and had an internal diameter of $0.66 \mathrm{~cm}(3 / 8 \mathrm{in.} \mathrm{nominal)]}$

Table C.4. Capillary Rheometer Data for $50 \%$ Beads and $50 \%$ Liquid Slurry [133 $\mathrm{cm}$ long tube with $.66 \mathrm{~cm}$ internal diameter ( $3 / 8 \mathrm{in}$. nominal)]

\begin{tabular}{|l|l|l|l||}
\hline Pressure Drop $(\mathrm{Pa})$ & Flow Rate $(\mathrm{cc} / \mathrm{sec})$ & Shear Rate $(1 / \mathrm{sec})$ & Viscosity $(\mathrm{Pa} * \mathrm{sec})$ \\
\hline \hline 1502.929 & .03302 & & \\
\hline 2687.91 & .083103 & 3.274219 & 1.01693 \\
\hline 4548.21 & .166575 & 6.199721 & .908767 \\
\hline 8785.216 & .332904 & 12.02701 & .904855 \\
\hline 12734.96 & .499724 & 18.28831 & .862597 \\
\hline 16332.26 & .666421 & 25.07233 & .80693 \\
\hline 19363.81 & .832873 & 30.7806 & .779288 \\
\hline 23116.75 & .99957 & 35.31042 & .810976 \\
\hline 27207.67 & 1.166912 & & \\
\hline
\end{tabular}

C. 4 


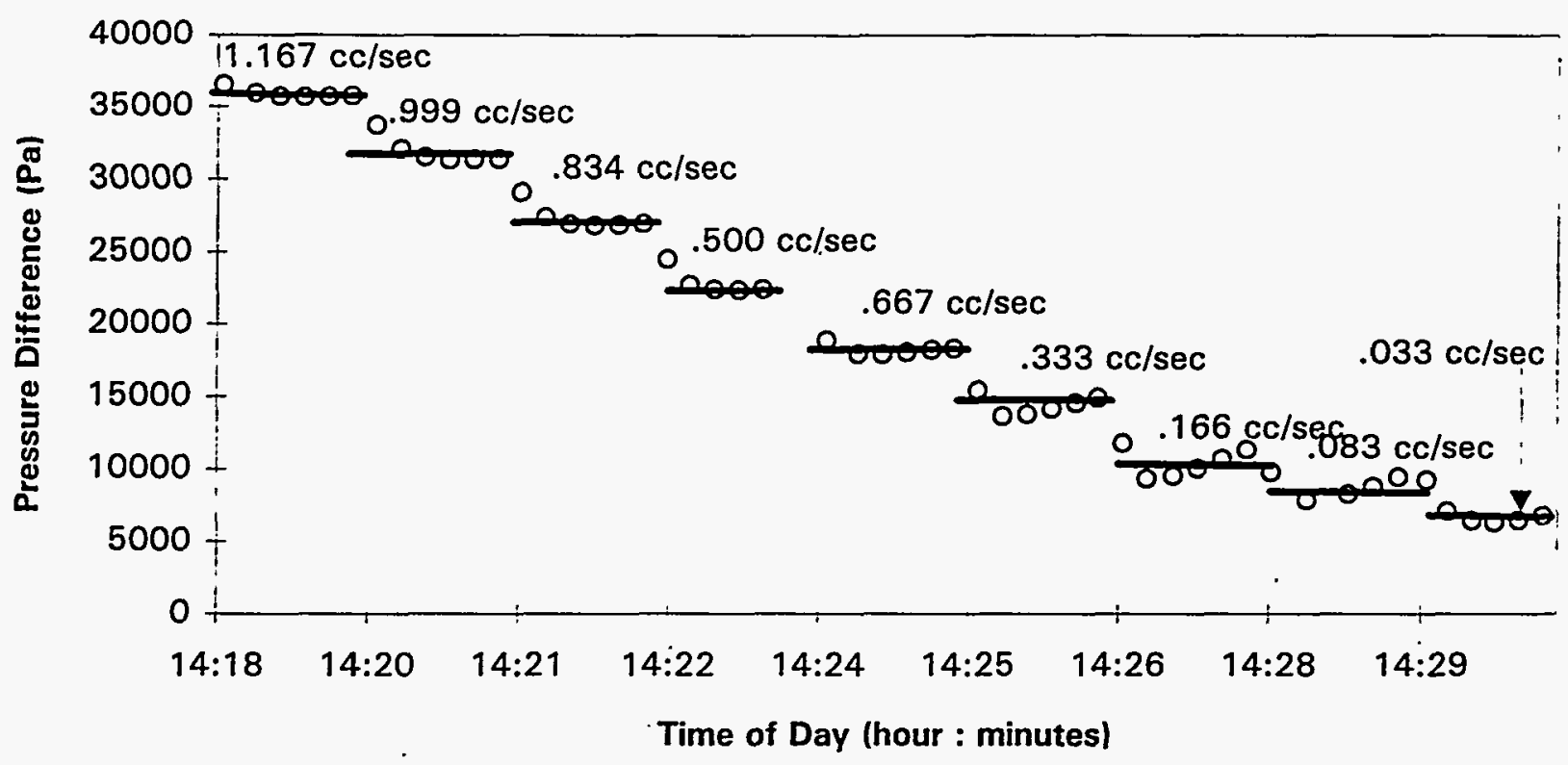

Figure C.5. Pressure Drop at Each Measured Flow for a Slurry Containing 50 vol\% Glass Beads and 50 vol\% of a Mixture of $80 \mathrm{wt} \%$ Glycerol in $20 \mathrm{wt} \%$ Water [Tube was $702 \mathrm{~cm}$ long with an internal diameter of $0.96 \mathrm{~cm}$ (1/2 in. nominal)]

Table C.5. Capillary Rheometer Data for 50\% Beads and 50\% Liquid Slurry $[702 \mathrm{~cm}$ long tube with $.96 \mathrm{~cm}$ internal diameter (1/2 in. nominal)]

\begin{tabular}{||l|l|l|l||}
\hline \hline Pressure Drop $(\mathrm{Pa})$ & Flow Rate $(\mathrm{cc} / \mathrm{sec})$ & Shear Rate $(1 / \mathrm{sec})$ & Viscosity $\left(\mathrm{Pa}{ }^{*} \mathrm{sec}\right)$ \\
\hline \hline 6511.708 & .03299 & & \\
\hline 8606.538 & .082858 & 1.541473 & 1.908919 \\
\hline 10463.19 & .166636 & 2.908981 & 1.229754 \\
\hline 14203.01 & .332904 & 4.734565 & 1.025641 \\
\hline 18072.06 & .499724 & 6.464727 & .955786 \\
\hline 22470.34 & .66639 & 8.19771 & .937156 \\
\hline 26914.51 & .83272 & 10.08104 & .912801 \\
\hline 31391.21 & .998742 & 12.03037 & .892122 \\
\hline 35726.18 & 1.164611 & & \\
\hline
\end{tabular}

C.5 


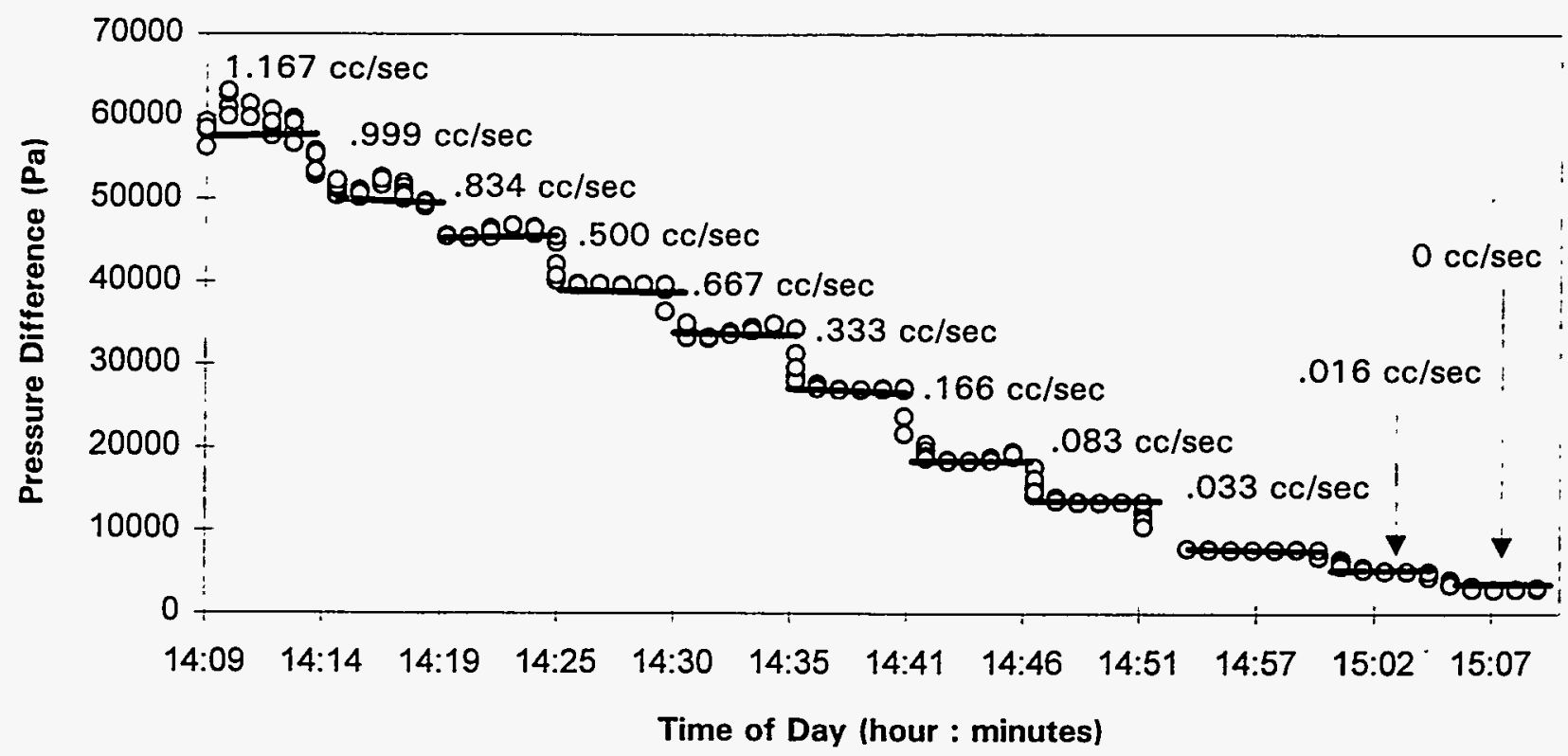

Figure C.6. Pressure Drop at Each Measured Flow for a Slurry Containing 50 vol\% Glass Beads, 25 vol\% nitrogen, and 25 vol\% of a Mixture of $80 \mathrm{wt} \%$ Glycerol in $20 \mathrm{wt} \%$ Water [Tube was $133 \mathrm{~cm}$ long with an internal diameter of $0.66 \mathrm{~cm}$ (3/8 in. nominal)]

Table C.6. Capillary Rheometer Data for 50\% Beads, $25 \%$ Gas, and $25 \%$ Liquid Slurry [133 cm long tube with $.66 \mathrm{~cm}$ internal diameter ( $3 / 8 \mathrm{in}$. nominal)]

\begin{tabular}{||l|l|l|l||}
\hline Pressure Drop $(\mathrm{Pa})$ & Flow Rate $(\mathrm{cc} / \mathrm{sec})$ & Shear Rate $(1 / \mathrm{sec})$ & Viscosity $(\mathrm{Pa}$ *sec) \\
\hline \hline 3038.473 & 0 & & \\
\hline 5345.988 & .016345 & & \\
\hline 7728.916 & .032811 & 1.393483 & 6.870699 \\
\hline 13582.06 & .083134 & 3.663399 & 4.592672 \\
\hline 18736.37 & .166621 & 7.417648 & 3.128985 \\
\hline 27120.9 & .332829 & 14.26146 & 2.355723 \\
\hline 33921.06 & .49984 & 21.39462 & 1.964034 \\
\hline 39651.41 & .666427 & 27.6003 & 1.779627 \\
\hline 45929.96 & .833088 & 33.78867 & 1.683872 \\
\hline 51372.54 & .999377 & 39.13509 & 1.626106 \\
\hline 58561.9 & 1.166789 & & \\
\hline
\end{tabular}

C.6 


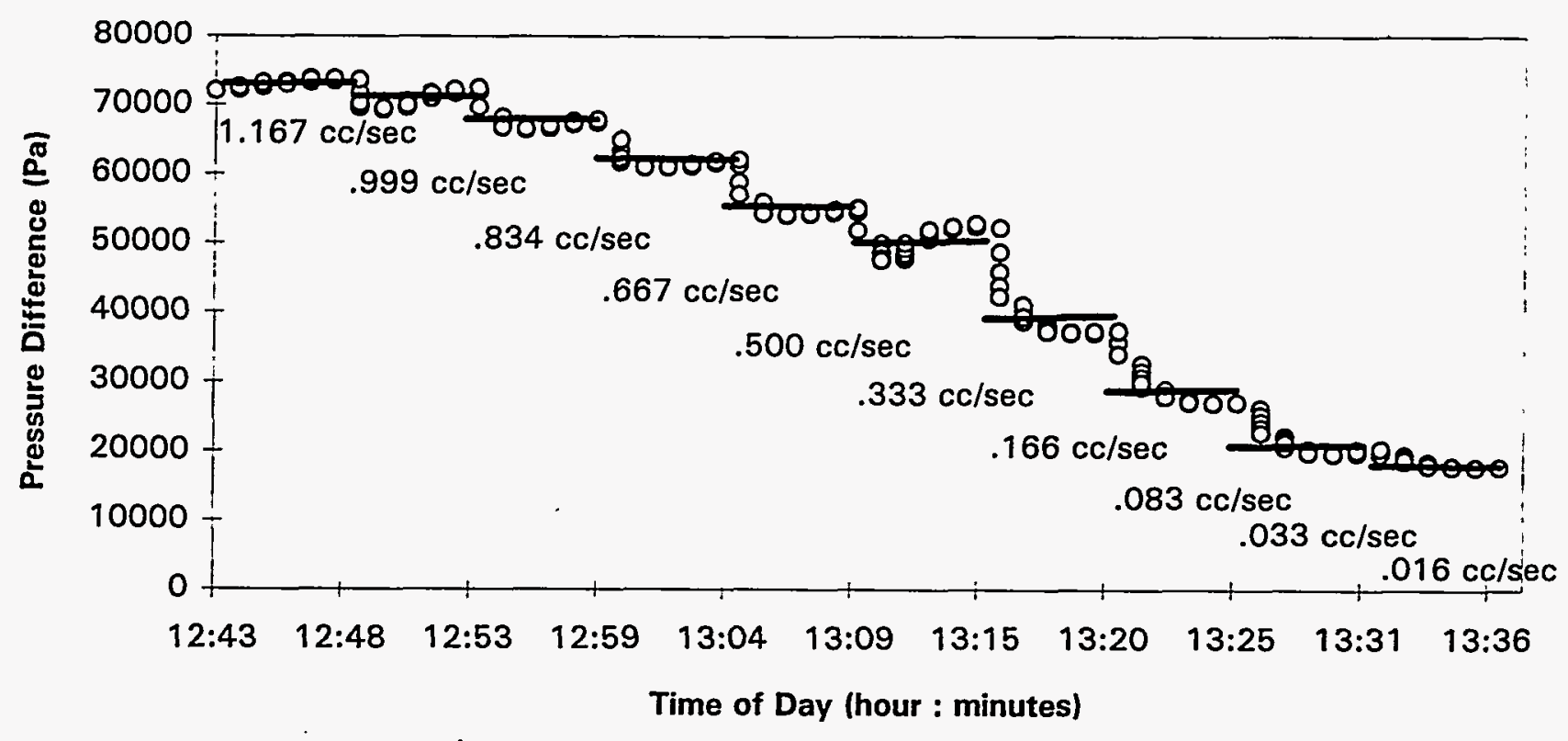

Figure C.7. Pressure Drop at Each Measured Flow for a Slurry Containing 50 vol\% Glass Beads, 25 vol\% Nitrogen, and 25 vol\% of a Mixture of $80 \mathrm{wt} \%$ Glycerol in $20 \mathrm{wt} \%$ Water

[Tube was $702 \mathrm{~cm}$ long with an internal diameter of $0.96 \mathrm{~cm}(1 / 2 \mathrm{in}$. nominal)]

Table C.7. Capillary Rheometer Data for 50\% Beads, $25 \%$ Gas, and $25 \%$ Liquid Slurry $[702 \mathrm{~cm}$ long tube with $.96 \mathrm{~cm}$ internal diameter (1/2 in. tube)]

\begin{tabular}{||l|l|l|l||}
\hline Pressure Drop $(\mathrm{Pa})$ & Flow Rate $(\mathrm{cc} / \mathrm{sec})$ & Shear Rate $(1 / \mathrm{sec})$ & Viscosity $(\mathrm{Pa} * \mathrm{sec})$ \\
\hline \hline 18400.61 & .016345 & & \\
\hline 20552.47 & .032885 & .799868 & 8.78498 \\
\hline 27793.42 & .083213 & 1.356027 & 7.007587 \\
\hline 37912.71 & .166575 & 2.521648 & 5.14038 \\
\hline 51359.82 & .333119 & 8.498286 & 2.06627 \\
\hline 54623 & .499908 & 11.74974 & 1.589434 \\
\hline 61578.01 & .666144 & 10.51389 & 2.002429 \\
\hline 67226.64 & .833087 & 14.45173 & 1.590437 \\
\hline 71007.79 & .999349 & 21.91033 & 1.108031 \\
\hline 73104.24 & 1.166119 & & \\
\hline
\end{tabular}

C.7 


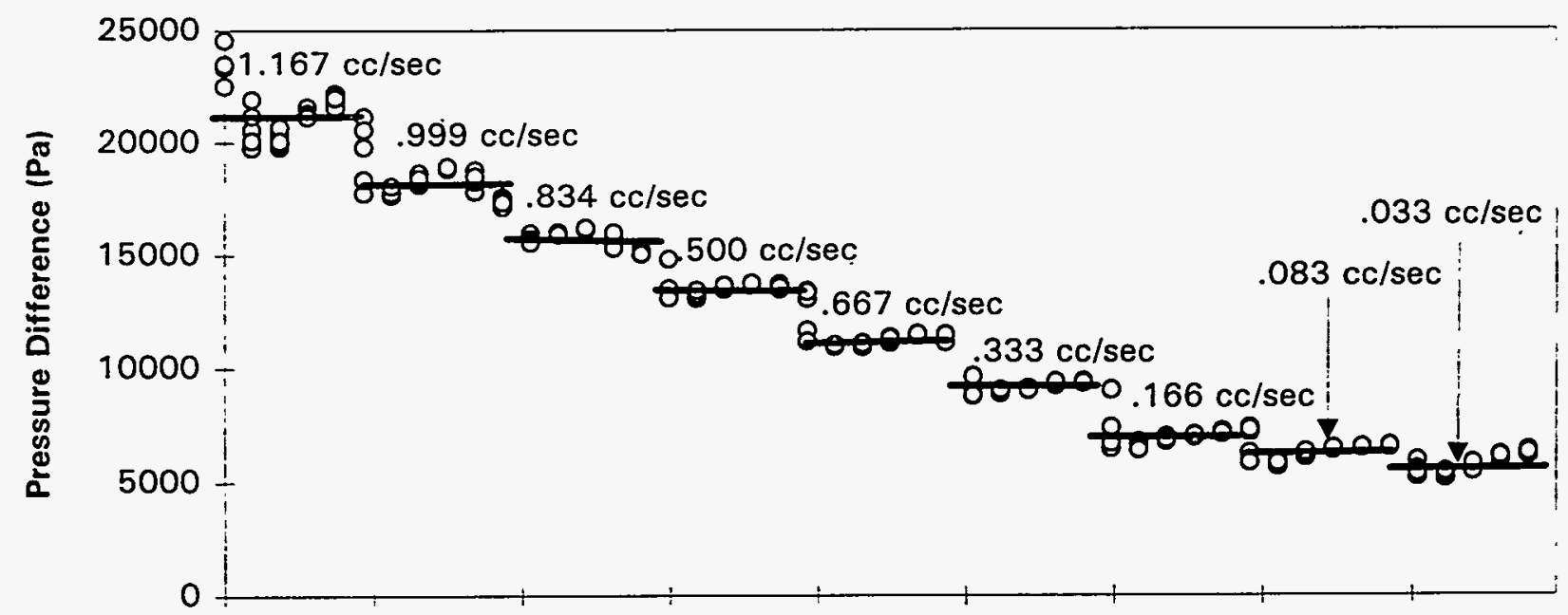

2:53 PM 2:58 PM 3:03 PM 3:09 PM 3:14 PM 3:19 PM 3:25 PM 3:30 PM 3:35 PM

Time of Day (hour : minutes)

Figure C.8. Pressure Drop at Each Measured Flow for a Slurry Containing 50 vol\% Glass Beads, 12.5 vol\% Nitrogen, and 37.5 vol\% of a Mixture of $80 \mathrm{wt} \%$ Glycerol in $20 \mathrm{wt} \%$ water [Tube was $133 \mathrm{~cm}$ long with an internal diameter of $0.66 \mathrm{~cm}$ (3/8 in. nominal)]

Table C.8. Capillary Rheometer Data for 50\% Beads, $12.5 \%$ Gas, and 37.5\% Liquid Slurry [133 $\mathrm{cm}$ long tube with $.66 \mathrm{~cm}$ internal diameter ( $3 / 8 \mathrm{in}$. tube)]

\begin{tabular}{|c|c|c|c|}
\hline Pressure Drop $(\mathrm{Pa})$ & Flow Rate (cc/sec) & Shear Rate (1/sec) & Viscosity $(\mathrm{Pa} * \mathrm{sec})$ \\
\hline 5772.545 & .032887 & & \\
\hline 6297.949 & .083241 & 8.791441 & .887408 \\
\hline 6961.596 & .16661 & 12.9106 & .667954 \\
\hline 9159.995 & .332914 & 15.39054 & .737268 \\
\hline 11230.61 & .499857 & 21.12047 & .658694 \\
\hline 13488.1 & .666288 & 26.43711 & .632006 \\
\hline 15820.43 & .833224 & 31.84798 & .615348 \\
\hline 18329.18 & .999407 & 36.94442 & .61458 \\
\hline 21061.87 & 1.166898 & . & \\
\hline
\end{tabular}




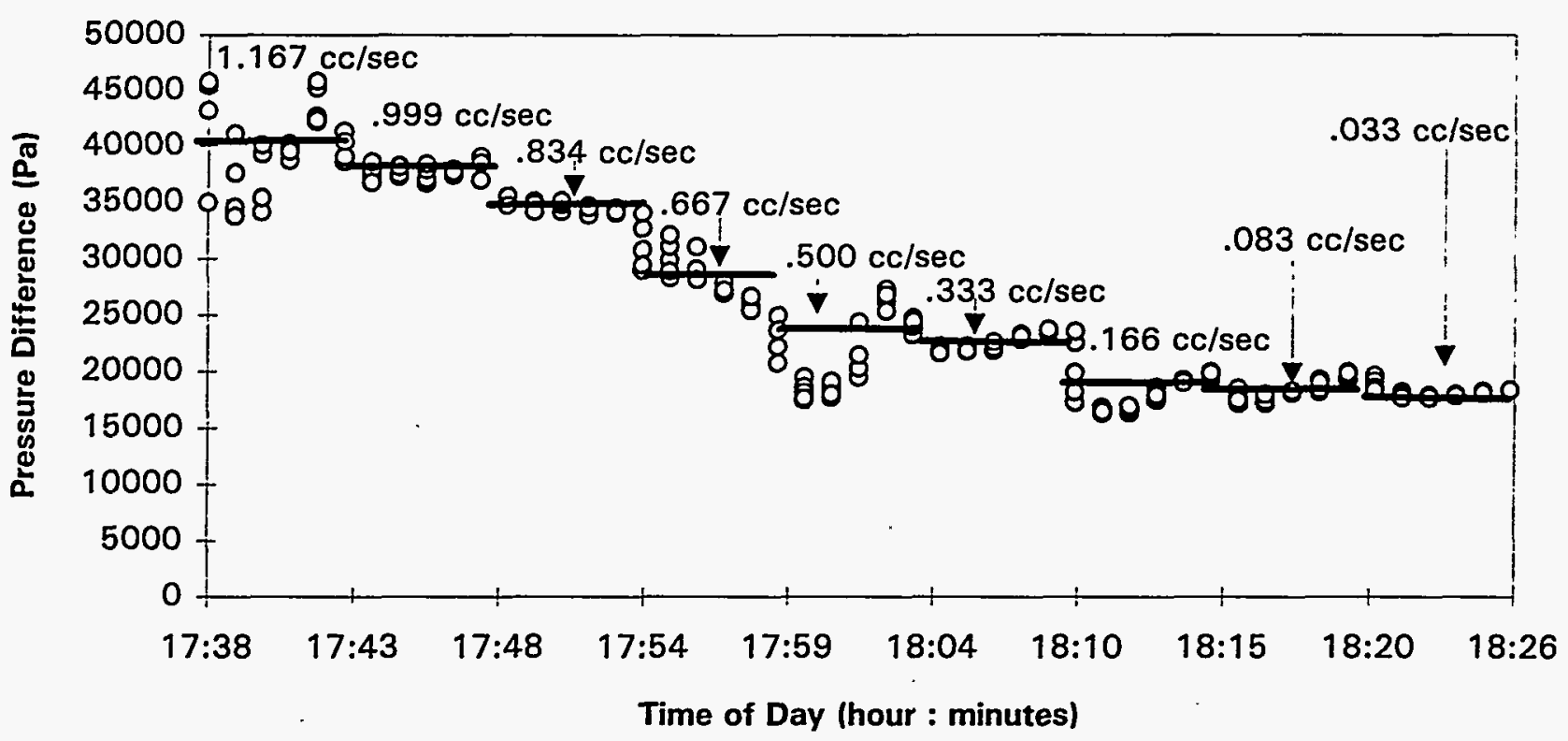

Figure C.9. Pressure Drop at Each Measured Flow for a Slurry Containing 50 vol\% Glass Beads, 12.5 vol\% Nitrogen, and 37.5 vol\% of a Mixture of $80 \mathrm{wt} \%$ Glycerol in $20 \mathrm{wt} \%$ Water [Tube was $702 \mathrm{~cm}$ long with an internal diameter of $0.96 \mathrm{~cm}(1 / 2 \mathrm{in}$. nominal)]

Table C.9. Capillary Rheometer Data for 50\% Beads, $12.5 \%$ Gas, and $37.5 \%$ Liquid Slurry [702 $\mathrm{cm}$ long tube with $.96 \mathrm{~cm}$ internal diameter (1/2 in. tube)]

\begin{tabular}{||l|l|l|l||}
\hline \hline Pressure Drop $(\mathrm{Pa})$ & Flow Rate $(\mathrm{cc} / \mathrm{sec})$ & Shear Rate $(1 / \mathrm{sec})$ & Viscosity $(\mathrm{Pa} * \mathrm{sec})$ \\
\hline \hline 18029.24 & .032851 & & \\
\hline 18444.08 & .08325 & 8.466811 & .744787 \\
\hline 19305.44 & .166559 & 7.564573 & .87255 \\
\hline 22643.51 & .223879 & 8.432988 & .918031 \\
\hline 24131.8 & .499788 & 11.62833 & .709524 \\
\hline 28369.09 & .666314 & 8.613866 & 1.12601 \\
\hline 34474 & .833154 & 11.18692 & 1.053601 \\
\hline 37907.51 & .999521 & 15.92854 & .813662 \\
\hline 39989.84 & 1.166281 & &. \\
\hline \hline
\end{tabular}




\section{Distribution}

No. of

Copies

Offsite

12 DOE/Office of Scientific and Technical Information

S. Agnew

Los Alamos National Laboratory MS-C345, Group INC-4

P.O. Box 1663

Los Alamos, NM 87545

N. E. Bibler

Westinghouse Savannah River

Bldg. 773A, Room 108

Aiken, SC 29802

D. Ferrara

Westinghouse Savannah River

P.O. Box 686

Aiken, SC 29808

K. Pasamehmetoglu

Los Alamos National Laboratory

P.O. Box 1663

MS-K555

Los Alamos, NM 87545

B. C. Hudson

202 Northridge Port

Lindsborg, KS 67456

L. Kovach

NUCON

P.O. Box 29246

Columbus, OH 43229

D. Pepson

U.S. Department of Energy

EM 36/Trevion II

Washington, DC 20585-0002
No. of

Copies

W. W. Schulz

7200 Montgomery Blvd

Suite 124

Albuquerque, NM 87109-1581

R. A. Tennant

Los Alamos National Laboratory

Mailstop J565

P.O. Box 1663

Los Alamos, NM 87545

Onsite

3 DOE Richland Operations Office

R. F. Christensen

S7-54

G. Rosenwald

S7-54

Reading Room

A1-65

17 Westinghouse Hanford Company

H. Babad

S7-30

J. D. Hopkins

R2-11

J. Jewett

T6-09

G. D. Johnson (5)

S7-15

N. W. Kirch

R2-11

J. W. Lentsch

S7-15

N. G. McDuffie

S7-15

D. M. Ogden

H0-34

M. A. Payne

S7-14

D. A. Reynolds

R2-11

D. J. Sherwood

S7-15

D. A. Turner

S7-15

R. J. Van Vleet

Distr.1 
No. of

Copies

43 Pacific Northwest Laboratory

R. T. Allemann

K7-15

W. J. Apley

Z. I. Antoniak

S7-71

K7-15

R. M. Bean

S. Q. Bennett

J. W. Brothers (5)

S. A. Bryan

J. L. Buelt

C. J. Call

J. A. Campbell

J. B. Colson

J. D. Hudson

P. A. Gauglitz (10)
No. of

Copies

S. C. Goheen P8-08

B. M. Johnson, Jr. K1-78

R. L. McKay P7-19

L. R. Pederson K2-44

M. R. Powell P7-19

G. F. Schiefelbein - P8-38

L. A. Schienbein K5-20

C. W. Stewart K7-15

D. M. Strachan K2-44

D. S. Trent K7-15

B. M. Wise K2-12

Publishing Coordination K1-06

Technical Report Files (5) 